\author{
Board of Governors of the Federal Reserve System \\ International Finance Discussion Papers
}

Number 1023

July 2011

\title{
Optimal Monetary Policy in an Operational Medium-Sized DSGE Model
}

\author{
Malin Adolfson \\ Stefan Laséen \\ Jesper Lindé \\ Lars E.O. Svensson
}

NOTE: International Finance Discussion Papers are preliminary materials circulated to stimulate discussion and critical comment. References to International Finance Discussion Papers (other than an acknowledgment that the writer has had access to unpublished material) should be cleared with the author or authors. Recent IFDPs are available on the Web at www.federalreserve.gov/pubs/ifdp/. This paper can be downloaded without charge from the Social Science Research Network electronic library at www.ssrn.com. 


\title{
Optimal Monetary Policy in an Operational Medium-Sized DSGE Model*
}

\author{
Malin Adolfson ${ }^{a}$, Stefan Laséen ${ }^{a}$, Jesper Lindé $^{b}$, and Lars E.O. Svensson ${ }^{c}$ \\ ${ }^{a}$ Sveriges Riksbank \\ ${ }^{b}$ Federal Reserve Board \\ ${ }^{c}$ Sveriges Riksbank, Stockholm University, CEPR, and NBER
}

July 2011

\begin{abstract}
We show how to construct optimal policy projections in Ramses, the Riksbank's openeconomy medium-sized DSGE model for forecasting and policy analysis. Bayesian estimation of the parameters of the model indicates that they are relatively invariant to alternative policy assumptions and supports our view that the model parameters may be regarded as unaffected by the monetary policy specification. We discuss how monetary policy, and in particular the choice of output gap measure, affects the transmission of shocks. Finally, we use the model to assess the recent Great Recession in the world economy and how its impact on the economic development in Sweden depends on the conduct of monetary policy. This provides an illustration on how Rames incoporates large international spillover effects.
\end{abstract}

JEL Classification: E52, E58

Keywords: Optimal monetary policy, instrument rules, optimal policy projections, openeconomy DSGE models

\footnotetext{
${ }^{*}$ We are grateful for helpful comments from Günter Coenen, Lee Ohanian, Frank Smets, and participants in the Second Oslo Workshop on Monetary Policy, the Central Bank Workshop on Macroeconomic Modelling, Oslo, the conference on New Perspectives on Monetary Policy Design, Barcelona, the Lindahl Lectures, Uppsala, the conference on Quantitative Approaches to Monetary Policy in Open Economies, Atlanta, and seminars at the Riksbank and the Institute for International Economic Studies. All remaining errors are ours. The views, analysis, and conclusions in this paper are solely the responsibility of the authors and should not be interpreted as reflecting the views of those of other members of the Riksbank's staff or executive board, or the Board of Governors of the Federal Reserve System or of any other person associated with the Federal Reserve System.
} 


\section{Contents}

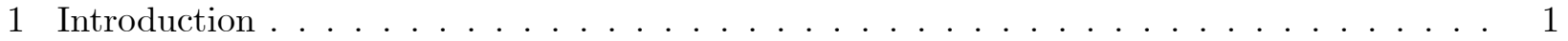

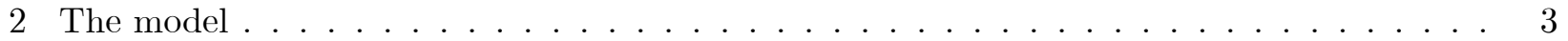

2.1 Domestic goods firms . . . . . . . . . . . . . . . . . . 4

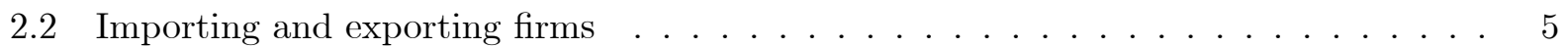

2.3 Households . . . . . . . . . . . . . . . . . . . . . . . 6

2.4 Structural shocks, government, foreign economy . . . . . . . . . . . 8

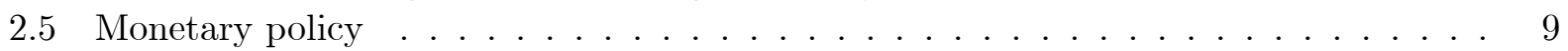

2.6 Model solution . . . . . . . . . . . . . . . . . . . . . . 11

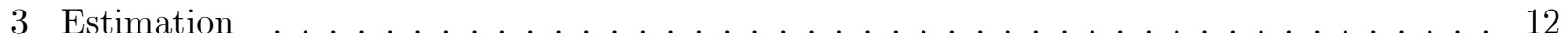

3.1 Data, prior distributions, and calibrated parameters . . . . . . . . . . 12

3.2 Estimation results . . . . . . . . . . . . . . . . . . . . . 14

4 Monetary policy and the transmission of shocks . . . . . . . . . . . . 17

5 Optimal policy projections and the Great Recession . . . . . . . . . . . . . . 20

5.1 Information and data . . . . . . . . . . . . . . . 20

5.2 The projection model and optimal projections . . . . . . . . . . . . . 21

5.3 An application to the Great Recession . . . . . . . . . . . . . . . . . 23

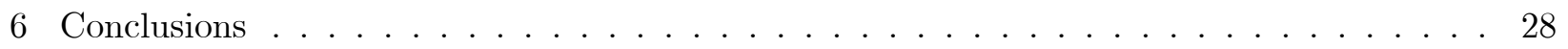

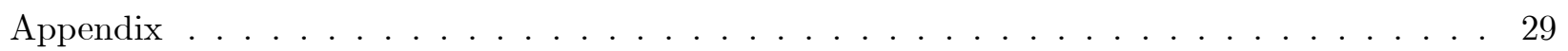

A Ramses in some detail . . . . . . . . . . . . . . . . . . . . . . 29

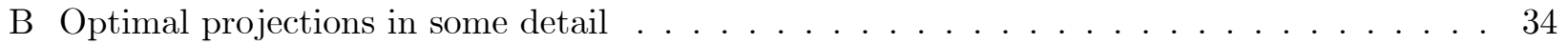

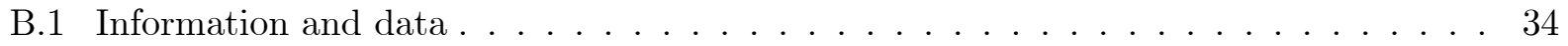

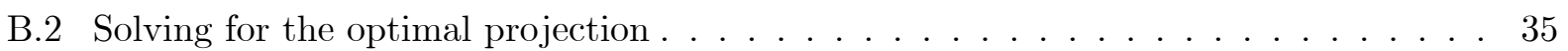

B.3 Determination of the initial Lagrange multipliers . . . . . . . . . . . . . . 36

B.4 Projections with an arbitrary instrument rule . . . . . . . . . . . 37

C Flexprice equilibrium and alternative concepts of potential output . . . . . . . . . 38

C.1 Unconditional potential output . . . . . . . . . . . . . . . . . . . . 40

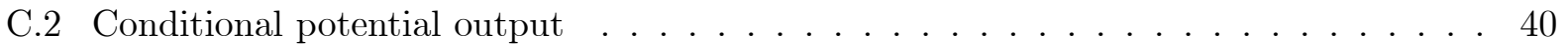

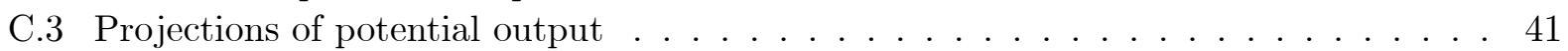

C.4 Output gaps . . . . . . . . . . . . . . . . . . . . . . . 42 


\section{Introduction}

We study optimal monetary policy in Ramses, the main model used at Sveriges Riksbank for forecasting and policy analysis. Ramses is an estimated small open-economy dynamic stochastic general equilibrium (DSGE) model, developed by Adolfson, Laséen, Lindé, and Villani (ALLV) [4] and [3].

By optimal monetary policy we mean policy that minimizes an intertemporal loss function. The intertemporal loss function is a discounted sum of expected future period losses. We choose a quadratic period loss function that corresponds to flexible inflation targeting and is the weighted sum of three terms: the squared inflation gap between 4-quarter CPI inflation and the inflation target, the squared output gap between output and potential output, and the squared quarterly change in the Riksbank's instrument rate, the repo rate. We interpret such a loss function as consistent with flexible inflation targeting and the Riksbank's mandate, which implies that monetary policy is directed towards stabilizing both inflation around an inflation target of 2 percent and resource utilization around a normal level $([37]) .^{1}$

A fundamental assumption in our analysis is that Ramses is a structural model whose parameters are invariant to the changes in monetary policy we consider. We estimate the model parameters with Bayesian techniques under different assumptions about the conduct of monetary policy. First, as in ALLV [3], we estimate the model under the assumption that the Riksbank has followed a simple instrument rule during the inflation-targeting period which started in 1993:1. ${ }^{2}$ Second, we estimate the model under the assumption that the Riksbank has minimized an intertemporal loss function during the inflation-targeting period. The estimates of the instrument-rule and lossfunction parameters provide benchmarks for the subsequent policy analysis. A finding in the empirical analysis is that whether past policy of the Riksbank until 2007:3 (the end of the sample used) is better explained as following a simple instrument rule or minimizing a loss function depends on whether the simple instrument rule and the optimal policy rule has a white-noise policy shock (control error) or not. Without a shock in both rules, we find that optimal policy fits the data

\footnotetext{
${ }^{1}$ In some simple models, quadratic approximations of the welfare of a representative household results in a similar period loss function (Woodford [39]). Such approximations of household welfare are very model-dependent and reflect the particular distortions assumed in any given model. Household welfare is in any case hardly an operational centralbank objective, although it may be of interest and relevant to examine how household welfare in particular models is affected by central-bank policy. Such an undertaking is beyond the scope of the present paper, though.

2 The inflation-targeting period is assumed to start 1993:1 (the estimation sample in this paper ends 2007:3). Prior to this period (1986:1-1992:4), the conduct of policy is assumed to be given by a simple instrument rule. The switch to the inflation-targeting regime in 1993:1 is assumed to be completely unanticipated but expected to be permanent once it has occurred.
} 
equally well as the simple instrument rule. With a shock in both rules, there is a clear improvement in the empirical fit of both rules. Furthermore, the simple instrument rule has a slight empirical advantage relative to optimal policy. Hence, for the particular sample period in question, with policy shocks the simple instrument rule offers a slightly better characterization of monetary policy. Our results are hence slightly different than those reported by Wolden Bache, Brubakk, and Maih [38] on Norwegian data, which stems from the fact that they do not allow for a control error in their analysis.

One contribution of our paper is to provide a detailed analysis of how to do optimal policy projections in an estimated linear-quadratic model with forward-looking variables, extending on previous analysis by Svensson [29] and Svensson and Tetlow [35]. A key issue for a flexible inflationtargeting central bank is which measure of resource utilization to stabilize. We use the output gap as measure of resource utilization and study alternative definitions of potential output and the output gap, in order to make an assessment to what extent the formulation of the output gap in the loss function affects the conduct of monetary policy and propagation of shocks. More precisely, we report results from three alternative concepts of output gaps $\left(y_{t}-\bar{y}_{t}\right)$, deviations of actual (log) output $\left(y_{t}\right)$ from potential $(\log )$ output $\left(\bar{y}_{t}\right)$, in the loss function. One concept of output gap is the trend output gap where potential output is the trend output level, which is growing stochastically due to the unit-root stochastic technology shock in the model. A second concept is the unconditional output gap, where potential output is unconditional potential output, which is defined as the hypothetical output level that would exist if the economy would have had flexible prices and wages for a long time and would have been subject to a subset of the same shocks as the actual economy. Unconditional potential output therefore presumes different levels of the predetermined variables, including the capital stock, from those in the actual economy. A third concept is the conditional output gap, where potential output is conditional potential output, which is defined as the hypothetical output level that would arise if prices and wages suddenly become flexible in the current period and are expected to remain flexible in the future. Conditional potential output therefore depends on the existing current predetermined variables, including the current capital stock.

To illustrate how the policy maker's choice of output measure can influence the transmission of shocks we study impulse response functions to a persistent but stationary technology shock. According to the estimated model, shocks to total factor productivity is a dominant driver of business cycles in Sweden. In addition to its economic importance, this shock is also particularly interesting to study since it affects the various output gaps differently. Conditional and unconditional poten- 
tial output increases when a positive stationary technology shock hits the economy, whereas trend output by definition is independent of such shocks and only depends on permanent (unit-root) technology shocks.

With that analysis in hand, we report and discuss optimal policy projections for Sweden using data up to and including 2008:2. We use the model to interpret the economic development in Sweden just at the time when the world economy fell into a deep recession due to the collapse in the financial markets. We choose this period to highlight the sensitivity of the Swedish economy to foreign shocks. We show projections for the estimated instrument rule and for optimal policy with different output gaps in the loss function, which create different trade-offs for the central bank in stabilizing inflation and output.

The paper is organized as follows: Section 2 presents Ramses in more general modeling terms. Section 3 discusses the data and priors used in the estimation and presents estimation results for the various specifications of the model and policy. Section 4 presents and discusses impulse response functions to a technology shock with different output gaps in the loss function. Section 5 discusses how to construct optimal policy projections, and analyzes alternative projections for a policymaker during the recent Great Recession. Finally, section 6 presents a summary and some conclusions. Appendices A-B contain a detailed specification of Ramses and some other technical details.

\section{The model}

Ramses is a small open-economy DSGE model developed in a series of papers by ALLV [4] and [3]. The model economy consists of households, domestic goods firms, importing consumption and importing investment firms, exporting firms, a government, a central bank, and an exogenous foreign economy. Within each manufacturing sector there is a continuum of firms that each produces a differentiated good and sets prices according to an indexation variant of the Calvo model. Domestic as well as global production grows with technology that contains a stochastic unit-root, see Altig et al. [8].

In what follows we provide the optimization problems of the different firms and the households, and describe the behavior of the central bank. The log-linear approximation of the model is presented in appendix A. 


\subsection{Domestic goods firms}

The domestic goods firms produce their goods using capital and labor inputs, and sell them to a retailer which transforms the intermediate products into a homogenous final good that in turn is sold to the households.

The final domestic good is a composite of a continuum of differentiated intermediate goods, each supplied by a different firm. Output, $Y_{t}$, of the final domestic good is produced with the constant elasticity of substitution (CES) function

$$
Y_{t}=\left[\int_{0}^{1}\left(Y_{i t}\right)^{\frac{1}{\lambda_{t}^{d}}} d i\right]^{\lambda_{t}^{d}}, \quad 1 \leq \lambda_{t}^{d}<\infty
$$

where $Y_{i t}, 0 \leq i \leq 1$, is the input of intermediate good $i$ and $\lambda_{t}^{d}$ is a stochastic process that determines the time-varying flexible-price markup in the domestic goods market. The production of the intermediate good $i$ by intermediate-good firm $i$ is given by

$$
Y_{i t}=z_{t}^{1-\alpha} \epsilon_{t} K_{i t}^{\alpha} H_{i t}^{1-\alpha}-z_{t} \phi
$$

where $z_{t}$ is a unit-root technology shock common to the domestic and foreign economies, $\epsilon_{t}$ is a domestic covariance stationary technology shock, $K_{i t}$ the capital stock and $H_{i t}$ denotes homogeneous labor hired by the $i^{t h}$ firm. A fixed cost $z_{t} \phi$ is included in the production function. We set this parameter so that profits are zero in steady state, following Christiano et al. [11].

We allow for working capital by assuming that a fraction $\nu$ of the intermediate firms' wage bill has to be financed in advance through loans from a financial intermediary. Cost minimization yields the following nominal marginal cost for intermediate firm $i$ :

$$
\mathrm{MC}_{i t}^{d}=\frac{1}{(1-\alpha)^{1-\alpha}} \frac{1}{\alpha^{\alpha}}\left(R_{t}^{k}\right)^{\alpha}\left[W_{t}\left(1+\nu\left(R_{t-1}-1\right)\right)\right]^{1-\alpha} \frac{1}{z_{t}^{1-\alpha}} \frac{1}{\epsilon_{t}},
$$

where $R_{t}^{k}$ is the gross nominal rental rate per unit of capital, $R_{t-1}$ the gross nominal (economy wide) interest rate, and $W_{t}$ the nominal wage rate per unit of aggregate, homogeneous, labor $H_{i t}$.

Each of the domestic goods firms is subject to price stickiness through an indexation variant of the Calvo [10] model. Each intermediate firm faces in any period a probability $1-\xi_{d}$ that it can reoptimize its price. The reoptimized price is denoted $P_{t}^{d, n e w}$. For the firms that are not allowed to reoptimize their price, we adopt an indexation scheme with partial indexation to the current inflation target, $\bar{\pi}_{t+1}^{c}$, since there is a perceived (time-varying) CPI inflation target in the model, 
and partial indexation to last period's inflation rate in order to allow for a lagged pricing term in the Phillips curve

$$
P_{t+1}^{d}=\left(\pi_{t}^{d}\right)^{\kappa_{d}}\left(\bar{\pi}_{t+1}^{c}\right)^{1-\kappa_{d}} P_{t}^{d}
$$

where $P_{t}^{d}$ is the price level, $\pi_{t}^{d}=P_{t+1}^{d} / P_{t}^{d}$ is gross inflation in the domestic sector, and $\kappa_{d}$ is an indexation parameter. The different firms maximize profits taking into account that there might not be a chance to optimally change the price in the future. Firm $i$ therefore faces the following optimization problem when setting its price

$$
\begin{gathered}
\max _{P_{t}^{d, \text { new }}} \mathrm{E}_{t} \sum_{s=0}^{\infty}\left(\beta \xi_{d}\right)^{s} v_{t+s}\left[\left(\left(\pi_{t}^{d} \pi_{t+1}^{d} \ldots \pi_{t+s-1}^{d}\right)^{\kappa_{d}}\left(\bar{\pi}_{t+1}^{c} \bar{\pi}_{t+2}^{c} \ldots \bar{\pi}_{t+s}^{c}\right)^{1-\kappa_{d}} P_{t}^{d, \text { new }}\right) Y_{i, t+s}\right. \\
\left.-\mathrm{MC}_{i, t+s}^{d}\left(Y_{i, t+s}+z_{t+s} \phi^{j}\right)\right]
\end{gathered}
$$

where the firm is using the stochastic household discount factor $\left(\beta \xi_{d}\right)^{s} v_{t+s}$ to make profits conditional upon utility. $\beta$ is the discount factor, and $v_{t+s}$ the marginal utility of the households' nominal income in period $t+s$, which is exogenous to the intermediate firms.

\subsection{Importing and exporting firms}

The importing consumption and importing investment firms buy a homogenous good at price $P_{t}^{*}$ in the world market, and convert it into a differentiated good through a brand naming technology. The exporting firms buy the (homogenous) domestic final good at price $P_{t}^{d}$ and turn this into a differentiated export good through the same type of brand naming. The nominal marginal cost of the importing and exporting firms are thus $S_{t} P_{t}^{*}$ and $P_{t}^{d} / S_{t}$, respectively, where $S_{t}$ is the nominal exchange rate (domestic currency per unit of foreign currency). The differentiated import and export goods are subsequently aggregated by an import consumption, import investment and export packer, respectively, so that the final import consumption, import investment, and export good is each a CES composite according to the following:

$$
C_{t}^{m}=\left[\int_{0}^{1}\left(C_{i t}^{m}\right)^{\frac{1}{\lambda_{t}^{m c}}} d i\right]^{\lambda_{t}^{m c}}, \quad I_{t}^{m}=\left[\int_{0}^{1}\left(I_{i t}^{m}\right)^{\frac{1}{\lambda_{t}^{m i}}} d i\right]^{\lambda_{t}^{m i}}, \quad X_{t}=\left[\int_{0}^{1}\left(X_{i t}\right)^{\frac{1}{\lambda_{t}^{x}}} d i\right]^{\lambda_{t}^{x}},
$$

where $1 \leq \lambda_{t}^{j}<\infty$ for $j=\{m c, m i, x\}$ is the time-varying flexible-price markup in the import consumption $(m c)$, import investment $(m i)$ and export $(x)$ sector. By assumption the continuum of consumption and investment importers invoice in the domestic currency and exporters in the foreign currency. To allow for short-run incomplete exchange rate pass-through to import as well as export prices we introduce nominal rigidities in the local currency price. This is modeled through 
the same type of Calvo setup as above. The price setting problems of the importing and exporting firms are completely analogous to that of the domestic firms in equation (2.5). ${ }^{3}$ In total there are thus four specific Phillips curve relations determining inflation in the domestic, import consumption, import investment and export sectors.

\subsection{Households}

There is a continuum of households which attain utility from consumption, leisure and real cash balances. The preferences of household $j$ are given by

$$
\mathrm{E}_{0}^{j} \sum_{t=0}^{\infty} \beta^{t}\left[\zeta_{t}^{c} \ln \left(C_{j t}-b C_{j, t-1}\right)-\zeta_{t}^{h} A_{L} \frac{\left(h_{j t}\right)^{1+\sigma_{L}}}{1+\sigma_{L}}+A_{q} \frac{\left(\frac{Q_{j t}}{z_{t} P_{t}^{d}}\right)^{1-\sigma_{q}}}{1-\sigma_{q}}\right]
$$

where $C_{j t}, h_{j t}$ and $Q_{j t} / P_{t}^{d}$ denote the $j^{\text {th }}$ household's levels of aggregate consumption, labor supply and real cash holdings, respectively. Consumption is subject to habit formation through $b C_{j, t-1}$, such that the household's marginal utility of consumption is increasing in the quantity of goods consumed last period. $\zeta_{t}^{c}$ and $\zeta_{t}^{h}$ are persistent preference shocks to consumption and labor supply, respectively. Households consume a basket of domestically produced goods $\left(C_{t}^{d}\right)$ and imported products $\left(C_{t}^{m}\right)$ which are supplied by the domestic and importing consumption firms, respectively. Aggregate consumption is assumed to be given by the following CES function:

$$
C_{t}=\left[\left(1-\omega_{c}\right)^{1 / \eta_{c}}\left(C_{t}^{d}\right)^{\left(\eta_{c}-1\right) / \eta_{c}}+\omega_{c}^{1 / \eta_{c}}\left(C_{t}^{m}\right)^{\left(\eta_{c}-1\right) / \eta_{c}}\right]^{\eta_{c} /\left(\eta_{c}-1\right)}
$$

where $\omega_{c}$ is the share of imports in consumption, and $\eta_{c}$ is the elasticity of substitution across consumption goods.

The households can invest in their stock of capital, save in domestic bonds and/or foreign bonds and hold cash. The households invest in a basket of domestic and imported investment goods to form the capital stock, and decide how much capital to rent to the domestic firms given costs of adjusting the investment rate. The households can increase their capital stock by investing in additional physical capital $\left(I_{t}\right)$, taking one period to come in action. The capital accumulation equation is given by

$$
K_{t+1}=(1-\delta) K_{t}+\Upsilon_{t}\left[1-\tilde{S}\left(I_{t} / I_{t-1}\right)\right] I_{t},
$$

\footnotetext{
3 Total export demand satisfies $C_{t}^{x}+I_{t}^{x}=\left[\frac{P_{t}^{x}}{P_{t}^{*}}\right]^{-\eta_{f}} Y_{t}^{*}$, where $C_{t}^{x}$ and $I_{t}^{x}$ is demand for consumption and investment goods, respectively; $P_{t}^{x}$ the export price; $P_{t}^{*}$ the foreign price level; $Y_{t}^{*}$ foreign output and $\eta_{f}$ the elasticity of substitution across foreign goods.
} 
where $\tilde{S}\left(I_{t} / I_{t-1}\right)$ determines the investment adjustment costs through the estimated parameter $\tilde{S}^{\prime \prime}$, and $\Upsilon_{t}$ is a stationary investment-specific technology shock. Total investment is assumed to be given by a CES aggregate of domestic and imported investment goods ( $I_{t}^{d}$ and $I_{t}^{m}$, respectively) according to

$$
I_{t}=\left[\left(1-\omega_{i}\right)^{1 / \eta_{i}}\left(I_{t}^{d}\right)^{\left(\eta_{i}-1\right) / \eta_{i}}+\omega_{i}^{1 / \eta_{i}}\left(I_{t}^{m}\right)^{\left(\eta_{i}-1\right) / \eta_{i}}\right]^{\eta_{i} /\left(\eta_{i}-1\right)},
$$

where $\omega_{i}$ is the share of imports in investment, and $\eta_{i}$ is the elasticity of substitution across investment goods.

Each household is a monopoly supplier of a differentiated labor service which implies that they can set their own wage, see Erceg, Henderson and Levin [16]. After having set their wage, households supply the firms' demand for labor,

$$
h_{j t}=\left[\frac{W_{j t}}{W_{t}}\right]^{\frac{\lambda_{w}}{1-\lambda_{w}}} H_{t},
$$

at the going wage rate. Each household sells its labor to a firm which transforms household labor into a homogenous good that is demanded by each of the domestic goods producing firms. Wage stickiness is introduced through the Calvo [10] setup, where household $j$ reoptimizes its nominal wage rate $W_{j t}^{\text {new }}$ according to the following ${ }^{4}$

$$
\begin{gathered}
\max _{W_{j t}^{\text {new }}} \mathrm{E}_{t} \sum_{s=0}^{\infty}\left(\beta \xi_{w}\right)^{s}\left[-\zeta_{t+s}^{h} A_{L} \frac{\left(h_{j, t+s}\right)^{1+\sigma_{L}}}{1+\sigma_{L}}+\right. \\
\left.v_{t+s} \frac{\left(1-\tau_{t+s}^{y}\right)}{\left(1+\tau_{t+s}^{w}\right)}\left(\left(\pi_{t}^{c} \ldots \pi_{t+s-1}^{c}\right)^{\kappa_{w}}\left(\bar{\pi}_{t+1}^{c} \ldots \bar{\pi}_{t+s}^{c}\right)^{\left(1-\kappa_{w}\right)}\left(\mu_{z, t+1} \ldots \mu_{z, t+s}\right) W_{j t}^{\text {new }}\right) h_{j, t+s}\right],
\end{gathered}
$$

where $\xi_{w}$ is the probability that a household is not allowed to reoptimize its wage, $\tau_{t}^{y}$ a labor income tax, $\tau_{t}^{w}$ a pay-roll tax (paid for simplicity by the households), and $\mu_{z t}=z_{t} / z_{t-1}$ is the growth rate of the unit-root technology shock.

The choice between domestic and foreign bond holdings balances into an arbitrage condition pinning down expected exchange rate changes (that is, an uncovered interest rate parity condition). To ensure a well-defined steady-state in the model, we assume that there is premium on the foreign bond holdings which depends on the aggregate net foreign asset position of the domestic households, see, for instance, Schmitt-Grohé and Uribe [24]. Compared to a standard setting the risk premium is allowed to be negatively correlated with the expected change in the exchange rate (that is, the expected depreciation), following the evidence discussed in for example Duarte and Stockman [15].

\footnotetext{
4 For the households that are not allowed to reoptimize, the indexation scheme is $W_{j, t+1}=$ $\left(\pi_{t}^{c}\right)^{\kappa_{w}}\left(\bar{\pi}_{t+1}^{c}\right)^{\left(1-\kappa_{w}\right)} \mu_{z, t+1} W_{j t}$, where $\kappa_{w}$ is an indexation parameter.
} 
For a detailed discussion and evaluation of this modification see ALLV [3]. The risk premium is given by:

$$
\Phi\left(a_{t}, S_{t}, \tilde{\phi}_{t}\right)=\exp \left(-\tilde{\phi}_{a}\left(a_{t}-\bar{a}\right)-\tilde{\phi}_{s}\left(\frac{E_{t} S_{t+1}}{S_{t}} \frac{S_{t}}{S_{t-1}}-1\right)+\tilde{\phi}_{t}\right)
$$

where $a_{t} \equiv\left(S_{t} B_{t}^{*}\right) /\left(P_{t} z_{t}\right)$ is the net foreign asset position, and $\tilde{\phi}_{t}$ is a shock to the risk premium.

To clear the final goods market, the foreign bond market, and the loan market for working capital, the following three constraints must hold in equilibrium:

$$
\begin{gathered}
C_{t}^{d}+I_{t}^{d}+G_{t}+C_{t}^{x}+I_{t}^{x} \leq z_{t}^{1-\alpha} \epsilon_{t} K_{t}^{\alpha} H_{t}^{1-\alpha}-z_{t} \phi \\
S_{t} B_{t+1}^{*}=S_{t} P_{t}^{x}\left(C_{t}^{x}+I_{t}^{x}\right)-S_{t} P_{t}^{*}\left(C_{t}^{m}+I_{t}^{m}\right)+R_{t-1}^{*} \Phi\left(a_{t-1}, \widetilde{\phi}_{t-1}\right) S_{t} B_{t}^{*}, \\
\nu W_{t} H_{t}=\mu_{t} M_{t}-Q_{t}
\end{gathered}
$$

where $G_{t}$ is government expenditures, $C_{t}^{x}$ and $I_{t}^{x}$ are the foreign demand for export goods which follow CES aggregates with elasticity $\eta_{f}$, and $\mu_{t}=M_{t+1} / M_{t}$ is the monetary injection by the central bank. When defining the demand for export goods, we introduce a stationary asymmetric (or foreign) technology shock $\tilde{z}_{t}^{*}=z_{t}^{*} / z_{t}$, where $z_{t}^{*}$ is the permanent technology level abroad, to allow for temporary differences in permanent technological progress domestically and abroad.

\subsection{Structural shocks, government, foreign economy}

The structural shock processes in the model are given by the univariate representation

$$
\hat{\varsigma}_{t}=\rho_{\varsigma} \hat{\varsigma}_{t-1}+\varepsilon_{\varsigma t}, \quad \varepsilon_{\varsigma t} \stackrel{i i d}{\sim} N\left(0, \sigma_{\varsigma}^{2}\right)
$$

where $\varsigma_{t}=\left\{\mu_{z t}, \epsilon_{t}, \lambda_{t}^{j}, \zeta_{t}^{c}, \zeta_{t}^{h}, \Upsilon_{t}, \tilde{\phi}_{t}, \varepsilon_{R t}, \bar{\pi}_{t}^{c}, \tilde{z}_{t}^{*}\right\}, j=\{d, m c, m i, x\}$, and a hat denotes the deviation of a log-linearized variable from a steady-state level $\left(\hat{v}_{t} \equiv d v_{t} / v\right.$ for any variable $v_{t}$, where $v$ is the steady-state level). $\lambda_{t}^{j}$ and $\varepsilon_{R t}$ are assumed to be white noise (that is, $\rho_{\lambda^{j}}=0, \rho_{\varepsilon_{R}}=0$ ).

The government spends resources on consuming part of the domestic good, and collects taxes from the households. The resulting fiscal surplus/deficit plus the seigniorage are assumed to be transferred back to the households in a lump sum fashion. Consequently, there is no government debt. The fiscal policy variables - taxes on labor income $\left(\hat{\tau}_{t}^{y}\right)$, consumption $\left(\hat{\tau}_{t}^{c}\right)$, and the payroll $\left(\hat{\tau}_{t}^{w}\right)$, together with (HP-detrended) government expenditures $\left(\hat{g}_{t}\right)$ - are assumed to follow an identified VAR model with two lags,

$$
\Theta_{0} \tau_{t}=\Theta_{1} \tau_{t-1}+\Theta_{2} \tau_{t-2}+S_{\tau} \varepsilon_{\tau t}
$$


where $\tau_{t} \equiv\left(\hat{\tau}_{t}^{y}, \hat{\tau}_{t}^{c}, \hat{\tau}_{t}^{w}, \hat{g}_{t}\right)^{\prime}, \varepsilon_{\tau t} \sim N\left(0, I_{\tau}\right), S_{\tau}$ is a diagonal matrix with standard deviations and $\Theta_{0}^{-1} S_{\tau} \varepsilon_{\tau t} \sim N\left(0, \Sigma_{\tau}\right)$.

Since Sweden is a small open economy we assume that the foreign economy is exogenous. Foreign inflation, $\pi_{t}^{*}$, output (HP-detrended), $\hat{y}_{t}^{*}$, and interest rate, $R_{t}^{*}$, are exogenously given by an identified VAR model with four lags,

$$
\Phi_{0} X_{t}^{*}=\Phi_{1} X_{t-1}^{*}+\Phi_{2} X_{t-2}^{*}+\Phi_{3} X_{t-3}^{*}+\Phi_{4} X_{t-4}^{*}+S_{x^{*}} \varepsilon_{x^{*} t}
$$

where $X_{t}^{*} \equiv\left(\pi_{t}^{*}, \hat{y}_{t}^{*}, R_{t}^{*}\right)^{\prime}, \varepsilon_{x^{*} t} \sim N\left(0, I_{x^{*}}\right), S_{X^{*}}$ is a diagonal matrix with standard deviations and $\Phi_{0}^{-1} S_{x^{*}} \varepsilon_{x^{*} t} \sim N\left(0, \Sigma_{x^{*}}\right)$. Given our assumption of equal substitution elasticities in foreign consumption and investment, these three variables suffice to describe the foreign economy in our model setup.

\subsection{Monetary policy}

Monetary policy is modeled in two different ways. First, we assume that the central bank minimizes an intertemporal loss function under commitment. Let the intertemporal loss function in period $t$ be

$$
\mathrm{E}_{t} \sum_{\tau=0}^{\infty} \delta^{\tau} L_{t+\tau},
$$

where $0<\delta<1$ is a discount factor, $L_{t}$ is the period loss that is given by

$$
L_{t}=\left(p_{t}^{c}-p_{t-4}^{c}-\bar{\pi}^{c}\right)^{2}+\lambda_{y}\left(y_{t}-\bar{y}_{t}\right)^{2}+\lambda_{\Delta i}\left(i_{t}-i_{t-1}\right)^{2}
$$

where the central bank's target variables are; model-consistent year-over-year CPI inflation rate, $p_{t}^{c}-p_{t-4}^{c}$, where $p_{t}^{c}$ denotes the $\log$ of $\mathrm{CPI}$ and $\bar{\pi}^{c}$ is the 2 percent inflation target; a measure of the output gap, $y_{t}-\bar{y}_{t}$; the first difference of the instrument rate, $i_{t}-i_{t-1}$, where $i_{t}$ denotes the Riksbank's instrument rate, the repo rate, and $\lambda_{y}$ and $\lambda_{\Delta i}$ are nonnegative weights on output-gap stabilization and instrument-rate smoothing, respectively. ${ }^{5}$

We report results from three alternative concepts of output gaps $\left(y_{t}-\bar{y}_{t}\right)$ as measures of resource utilization in the loss function. One concept of output gap is the trend output gap where potential output $\left(\bar{y}_{t}\right)$ is the trend output level, which is growing stochastically due to the unit-root stochastic technology shock in the model. A second concept is the unconditional output gap, where potential output is unconditional potential output, which is defined as the hypothetical output level that

\footnotetext{
${ }^{5}$ We use the 4-quarter CPI difference as a target variable rather than quarterly inflation since the Riksbank and other inflation-targeting central banks normally specify their inflation target as a 12-month rate.
} 
would exist if the economy would have had flexible prices and wages for a long time and would have been subject to the same shocks as the actual economy except mark-up shocks and shocks to taxes which are held constant at their steady-state levels. Unconditional potential output therefore presumes different levels of the predetermined variables, including the capital stock, from those in the actual economy. A third concept is the conditional output gap, where potential output is conditional potential output, which is defined as the hypothetical output level that would arise if prices and wages suddenly become flexible in the current period and are expected to remain flexible in the future. Conditional potential output therefore depends on the existing current predetermined variables, including the current capital stock. In precise form the three different concepts of potential output are

$$
\begin{gathered}
\bar{y}_{t}^{\text {trend }}=z_{t}, \\
\bar{y}_{t}^{\text {cond }}=F_{y}^{f} \cdot X_{t}, \\
\bar{y}_{t}^{\text {uncond }}=F_{y}^{f} \cdot X_{t}^{f},
\end{gathered}
$$

where $z_{t}$ is the unit-root technology shock, the row vector $F_{y}^{f}$. expresses output as a function of the predetermined state variables in the flex-price economy, $X_{t}$ is the vector of predetermined state variables in Ramses, and $X_{t}^{f}$ is the state vector in the economy with flexible prices and wages.

Second, we assume that monetary policy obeys an instrument rule, following Smets and Wouters [26]. Instead of optimizing an intertemporal loss function, the central bank is then assumed to adjust the short term interest rate in response to deviations of CPI inflation from the perceived inflation target, the trend output gap (measured as actual minus trend output), the real exchange rate $\left(\hat{x}_{t} \equiv \hat{S}_{t}+\hat{P}_{t}^{*}-\hat{P}_{t}^{c}\right)$ and the interest rate set in the previous period. The log-linearized instrument rule follows:

$$
\begin{aligned}
i_{t}= & \rho_{R} i_{t-1}+\left(1-\rho_{R}\right)\left[\widehat{\bar{\pi}}_{t}^{c}+r_{\pi}\left(\hat{\pi}_{t-1}^{c}-\widehat{\bar{\pi}}_{t}^{c}\right)+r_{y} \hat{y}_{t-1}+r_{x} \widehat{\tilde{x}}_{t-1}\right] \\
& +r_{\Delta \pi}\left(\hat{\pi}_{t}^{c}-\hat{\pi}_{t-1}^{c}\right)+r_{\Delta y}\left(\hat{y}_{t}-\hat{y}_{t-1}\right)+\varepsilon_{R t},
\end{aligned}
$$

where $i_{t} \equiv \hat{R}_{t}$ (the notation for the short nominal interest rate in Ramses), and $\varepsilon_{R t}$ is an uncorrelated monetary policy shock. Since $\hat{\pi}_{t}^{c}$ and $\hat{y}_{t}$ are forward-looking variables, this is an implicit instrument rule (see appendix B.4). ${ }^{6}$

\footnotetext{
${ }^{6}$ As reported in ALLV [3], the output gap resulting from trend output seems to more closely correspond to the measure of resource utilization that the Riksbank has been responding to historically rather than the unconditional output gap. Del Negro, Schorfheide, Smets, and Wouters [14] report similar results for the US.
} 


\subsection{Model solution}

After log-linearization, Ramses can be written in the following state-space form,

$$
\left[\begin{array}{c}
X_{t+1} \\
H x_{t+1 \mid t}
\end{array}\right]=A\left[\begin{array}{c}
X_{t} \\
x_{t}
\end{array}\right]+B i_{t}+\left[\begin{array}{c}
C \\
0
\end{array}\right] \varepsilon_{t+1}
$$

Here, $X_{t}$ is an $n_{X}$-vector of predetermined variables in period $t$ (where the period is a quarter); $x_{t}$ is an $n_{x}$-vector of forward-looking variables; $i_{t}$ is an $n_{i}$-vector of instruments (the forwardlooking variables and the instruments are the nonpredetermined variables); ${ }^{7} \varepsilon_{t}$ is an $n_{\varepsilon}$-vector of i.i.d. shocks with mean zero and covariance matrix $I_{n_{\varepsilon}} ; A, B$, and $C$, and $H$ are matrices of the appropriate dimension; and, for any variable $y_{t}, y_{t+\tau \mid t}$ denotes $\mathrm{E}_{t} y_{t+\tau}$, the rational expectation of $y_{t+\tau}$ conditional on information available in period $t$. The variables are measured as differences from steady-state values; thus their unconditional means are zero. The elements of the matrices $A, B, C$, and $H$ are estimated with Bayesian methods and are considered fixed and known for the policy simulations. Then the conditions for certainty equivalence are satisfied. Thus, we abstract from any consideration of model uncertainty in the formulation of optimal policy. ${ }^{8}$

The upper block of (2.21) provides $n_{X}$ equations that determine the $n_{X}$-vector $X_{t+1}$ in period $t+1$ for given $X_{t}, x_{t}, i_{t}$ and $\varepsilon_{t+1}$,

$$
X_{t+1}=A_{11} X_{t}+A_{12} x_{t}+B_{1} i_{t}+C \varepsilon_{t+1}
$$

where $A$ and $B$ are partitioned conformably with $X_{t}$ and $x_{t}$ as

$$
A \equiv\left[\begin{array}{ll}
A_{11} & A_{12} \\
A_{21} & A_{22}
\end{array}\right], \quad B=\left[\begin{array}{c}
B_{1} \\
B_{2}
\end{array}\right]
$$

The lower block provides $n_{x}$ equations that determine the $n_{x}$-vector $x_{t}$ in period $t$ for given $x_{t+1 \mid t}$, $X_{t}$, and $i_{t}$,

$$
x_{t}=A_{22}^{-1}\left(H x_{t+1 \mid t}-A_{21} X_{t}-B_{2} i_{t}\right) \text {. }
$$

We hence assume that the $n_{x} \times n_{x}$ submatrix $A_{22}$ is nonsingular. ${ }^{9}$

We assume that the central bank's $n_{Y}$-vector of target variables, measured as the difference from an $n_{Y}$-vector $Y^{*}$ of target levels, $Y_{t} \equiv\left(p_{t}^{c}-p_{t-4}^{c}-\bar{\pi}^{c}, y_{t}-\bar{y}_{t}, i_{t}-i_{t-1}\right) \prime$, can be written as a

\footnotetext{
7 A variable is predetermined if its one-period-ahead prediction error is an exogenous stochastic process (Klein [21]). For (2.21), the one-period-ahead prediction error of the predetermined variables is the stochastic vector $C \varepsilon_{t+1}$.

${ }^{8}$ Onatski and Williams [23] provide a thorough discussion of model uncertainty. Svensson and Williams [33] and [34] show how to compute optimal policies for Markov Jump-Linear-Quadratic systems, which provide a quite flexible way to model most kinds of relevant model uncertainty for monetary policy. Levin, Onatski, Williams and Williams [20] study optimal policy when the central bank faces uncertainty about the true structure of the economy (i.e., they look at the entire posterior distribution of the model parameters).

${ }^{9}$ Without loss of generality, we assume that the shocks $\varepsilon_{t}$ only enter in the upper block of $(2.21)$, since any shocks in the lower block of (2.21) can be redefined as additional predetermined variables and introduced in the upper block.
} 
linear function of the predetermined, forward-looking, and instrument variables,

$$
Y_{t}=D\left[\begin{array}{c}
X_{t} \\
x_{t} \\
i_{t}
\end{array}\right] \equiv\left[\begin{array}{lll}
D_{X} & D_{x} & D_{i}
\end{array}\right]\left[\begin{array}{c}
X_{t} \\
x_{t} \\
i_{t}
\end{array}\right],
$$

where $D$ is an $n_{Y} \times\left(n_{X}+n_{x}+n_{i}\right)$ matrix and partitioned conformably with $X_{t}, x_{t}$, and $i_{t}$. Assuming optimization of (2.18) under commitment in a timeless perspective, the resulting intertemporal equilibrium can then be described by the following difference equations,

$$
\begin{aligned}
{\left[\begin{array}{c}
x_{t} \\
i_{t}
\end{array}\right] } & =F\left[\begin{array}{c}
X_{t} \\
\Xi_{t-1}
\end{array}\right] \\
{\left[\begin{array}{c}
X_{t+1} \\
\Xi_{t}
\end{array}\right] } & =M\left[\begin{array}{c}
X_{t} \\
\Xi_{t-1}
\end{array}\right]+\left[\begin{array}{c}
C \\
0
\end{array}\right] \varepsilon_{t+1},
\end{aligned}
$$

for $t \geq 0$, where $X_{0}$ and $\Xi_{-1}$ are given. This system of difference equations can be solved with several alternative algorithms, for instance those developed by Klein [21] and Sims [25]. ${ }^{10}$ The choice and calculation of the initial $\Xi_{-1}$ is further discussed in footnote 14 and appendix B.3.

When policy instead is described by the simple instrument rule in (2.20), there exists $F$ and $M$ matrices such that the intertemporal equilibrium difference equations (2.26) and (2.27) are still valid but with $\Xi_{t}=0$ for $t \geq 0$.

\section{Estimation}

\subsection{Data, prior distributions, and calibrated parameters}

We use quarterly Swedish data for the period 1980:1-2007:3 and estimate the model using a Bayesian approach by placing a prior distribution on the structural parameters. ${ }^{11,12}$

As in ALLV [3], we include the following $n_{Z}=15$ variables among the observable variables: GDP deflator inflation $\left(\pi_{t}^{d}\right)$, real wage $\left(W_{t} / P_{t}^{d}\right)$, consumption $\left(C_{t}\right)$, investment $\left(I_{t}\right)$, real exchange rate $\left(\tilde{x}_{t}\right)$, short interest rate $\left(R_{t}\right)$, hours worked $\left(H_{t}\right)$, GDP $\left(Y_{t}\right)$, exports $\left(\tilde{X}_{t}\right)$, imports $\left(\tilde{M}_{t}\right)$, CPI inflation $\left(\pi_{t}^{\text {cpi }}\right)$, investment-deflator inflation $\left(\pi_{t}^{\text {def }, i}\right)$, foreign (trade-weighted) output $\left(Y_{t}^{*}\right)$, foreign inflation $\left(\pi_{t}^{*}\right)$, and foreign interest rate $\left(R_{t}^{*}\right)$. We use first differences of the quantities and the real

\footnotetext{
${ }^{10}$ See Svensson [29] and [30] for details of the derivation and the application of the Klein algorithm.

11 All data are from Statistics Sweden, except the repo rate which is from the Riksbank. The nominal wage is deflated by the GDP deflator. Foreign inflation, output, and interest rate are weighted together across Sweden's 20 largest trading partners in 1991 using weights from the IMF.

${ }^{12}$ In the data, the ratios of import and export to output are increasing from about 0.25 to 0.40 and from 0.21 to 0.50 , respectively, during the sample period. In the model, import and export are assumed to grow at the same rate as output. We have removed the excess trend in import and export in the data to make the export and import shares stationary. For all other variables we use the actual series (seasonally adjusted with the X12-method, except the variables in the GDP identity which were seasonally adjusted by Statistics Sweden).
} 
wage, since the unit-root technology shock induces a common stochastic trend in these variables, and derive the state-space representation for the following vector of observed variables,

$$
\begin{aligned}
Z_{t} \equiv & \left(\pi_{t}^{d}, \Delta \ln \left(W_{t} / P_{t}\right), \Delta \ln C_{t}, \Delta \ln I_{t}, \widehat{\widetilde{x}}_{t}, R_{t}, \hat{H}_{t}, \ldots\right. \\
& \left.\Delta \ln Y_{t}, \Delta \ln \tilde{X}_{t}, \Delta \ln \tilde{M}_{t}, \pi_{t}^{\mathrm{cpi}}, \pi_{t}^{\mathrm{def}, i}, \Delta \ln Y_{t}^{*}, \pi_{t}^{*}, R_{t}^{*}\right)^{\prime} .
\end{aligned}
$$

The growth rates are computed as quarterly log-differences, while the inflation and interest-rate series are measured as annualized quarterly rates. It should be noted that the stationary variables $\widehat{\widetilde{x}}_{t}$ and $\hat{H}_{t}$ are measured as deviations around the mean and the HP-filtered trend, that is, $\widehat{\widetilde{x}}_{t} \equiv$ $\left(\tilde{x}_{t}-\tilde{x}\right) / \tilde{x}$ and $\hat{H}_{t} \equiv\left(H_{t}-H_{t}^{\mathrm{HP}}\right) / H_{t}^{\mathrm{HP}}$, respectively. ${ }^{13}$ Finally, all real variables are measured in per-capita units.

We estimate 13 structural shocks, of which 8 follow $\operatorname{AR}(1)$ processes and 5 are assumed to be i.i.d. (as described in section 2.4). In addition to these, there are 8 shocks provided by the exogenous (pre-estimated) fiscal and foreign VARs, whose parameters are kept fixed throughout the estimation of the model (uninformative priors are used for these stochastic processes). The shocks enter in such a way that there is no stochastic singularity in the likelihood function.

To compute the likelihood function, the reduced-form solution of the model (2.26-2.27) is transformed into a state-space representation that maps the unobserved state variables into the observed data. ${ }^{14}$ The posterior mode and Hessian matrix evaluated at the mode is computed by standard numerical optimization routines (see Smets and Wouters [26] and the references there for details).

The parameters we choose to estimate pertain mostly to the nominal and real frictions in the model and the exogenous shock processes. ${ }^{15}$ Table 3.1 shows the assumptions for the prior distribution of the estimated parameters. For the model with a simple instrument rule, we choose identical priors for the parameters in the instrument rule before and after the adoption of an

\footnotetext{
13 The reason why we use a smooth HP-filtered trend for hours per capita, as opposed to a constant mean, is that there is a large and very persistent reduction in hours worked per capita during the recession in the beginning of the 1990s. Neglecting taking this reduction into account implies that the forecasting performance for hours per capita in the model deteriorates significantly, as documented in the forecasting exercises in ALLV [3]. Rather than imposing a discrete shift in hours in a specific time period, we therefore decided to remove a smooth HP trend from the variable. This choice is not particularly important for the parameter estimates, but has some impact on the 2-sided filtered estimates of the unobserved states of the economy.

${ }^{14}$ We use the Kalman filter to calculate the likelihood function of the observed variables. The period 1980:1$1985: 4$ is used to form a prior on the unobserved state variables in 1985:4, and the period 1986:1-2007:3 is used for inference. During estimation the Lagrange multipliers, $\Xi_{t}$, are updated through the Kalman filter just as the other state variables. When the instrument rule is active $\Xi_{t}$ equals zero, and in 1993:1, when policy (unexpectedly) switches to minimizing the loss function, we assume commmitment from scratch so that the initial Lagrange multipliers are zero.

${ }^{15}$ We choose to calibrate those parameters that we think are weakly identified by the variables that we include in the vector of observed data. These parameters are mostly related to the steady-state values of the observed variables (that is, the great ratios: $C / Y, I / Y$, and $G / Y)$. The parameters that we calibrate are set as follows: the money growth $\mu=1.010445$; the discount factor $\beta=0.999999$; the steady state growth rate of productivity $\mu_{z}=1.005455$; the depreciation rate $\tilde{\delta}=0.025$; the capital share in production $\alpha=0.25$; the share of imports in consumption and investment $\omega_{c}=0.35$ and $\omega_{i}=0.50$, respectively; the share of wage bill financed by loans $\nu=1$; the labour supply elasticity $\sigma_{L}=1$; the wage markup $\lambda_{w}=1.30$; inflation target persistence $\rho_{\pi}=0.975$; the steady-state tax rates on labour income and consumption $\tau^{y}=0.30$ and $\tau^{c}=0.24$, respectively; government expenditures-output ratio 0.30 ; and the subsitution elasticity between consumption goods $\eta_{c}=5$.
} 
inflation target in 1993:1. For the model with optimal policy during the inflation-targeting regime, we use very uninformative priors for the loss-function parameters $\left(\lambda_{y}\right.$ and $\left.\lambda_{\Delta i}\right)$, as indicated by the high standard deviations. As mentioned in the introduction, the switch from the simple instrument rule to the inflation-targeting regime in 1993:1 is modelled as unanticipated and expected to last forever once it has occurred.

Relative to other estimated small open-economy DSGE models (for instance, Justiniano and Preston [17]), the international spillover effects are relatively large due to the inclusion of a worldwide stochastic technology shock. This means that the open-economy aspects are of particular importance in our setting.

\subsection{Estimation results}

In table 3.1, we report the prior and estimated posterior distributions. Three posterior distributions are reported. The first, labeled "Simple inst rule", is under the assumption that the Riksbank has followed a simple instrument rule during the inflation-targeting period (see equation (2.20)). The second, labeled "Loss function", is under the assumption that the Riksbank has minimized a quadratic loss function under commitment during the inflation-targeting period, with the output gap in the loss function being the trend output gap (see equation (2.19)). In this case, the optimal policy rule does not include a policy shock. The third, labeled "Loss fn params", only estimates the two parameters in that loss function. ${ }^{16}$

\footnotetext{
${ }^{16}$ The estimations are based on allowing the inflation target to be time-varying. The parameter estimates are, however, robust to keeping the inflation target fixed at $2 \%$ during the the inflation-targeting period.
} 
Table 3.1: Prior and posterior distributions

\begin{tabular}{|c|c|c|c|c|c|c|c|c|c|c|}
\hline \multirow[t]{2}{*}{ Parameter } & & \multicolumn{3}{|c|}{ Prior distribution } & \multicolumn{6}{|c|}{ Posterior distribution } \\
\hline & & type & mean & $\begin{array}{l}\text { std.d. } \\
/ \text { df }\end{array}$ & $\begin{array}{l}\text { Simple } \\
\text { mode }\end{array}$ & $\begin{array}{c}\text { nst rule } \\
\text { std.d. } \\
\text { (Hess.) }\end{array}$ & $\begin{array}{l}\text { Loss } f \\
\text { mode }\end{array}$ & $\begin{array}{c}\text { ction } \\
\text { std.d. } \\
\text { (Hess.) }\end{array}$ & $\begin{array}{l}\text { Loss } f_{1} \\
\text { mode }\end{array}$ & $\begin{array}{c}\text { params } \\
\text { std.d. } \\
\text { (Hess.) }\end{array}$ \\
\hline Calvo wages & $\xi_{w}$ & beta & 0.750 & 0.050 & 0.719 & 0.045 & 0.719 & 0.042 & & \\
\hline Calvo domestic prices & $\xi_{d}$ & beta & 0.750 & 0.050 & 0.712 & 0.039 & 0.737 & 0.043 & & \\
\hline Calvo import cons. prices & $\xi_{m c}$ & beta & 0.750 & 0.050 & 0.868 & 0.018 & 0.859 & 0.016 & & \\
\hline Calvo import inv. prices & $\xi_{m i}$ & beta & 0.750 & 0.050 & 0.933 & 0.010 & 0.929 & 0.011 & & \\
\hline Calvo export prices & $\xi_{x}$ & beta & 0.750 & 0.050 & 0.898 & 0.019 & 0.889 & 0.025 & & \\
\hline Indexation wages & $\kappa_{w}$ & beta & 0.500 & 0.150 & 0.445 & 0.124 & 0.422 & 0.115 & & \\
\hline Indexation prices & $\kappa_{d}$ & beta & 0.500 & 0.150 & 0.180 & 0.051 & 0.173 & 0.050 & & \\
\hline Markup domestic & $\lambda_{f}$ & truncnormal & 1.200 & 0.050 & 1.192 & 0.049 & 1.176 & 0.050 & & \\
\hline Markup imported cons. & $\lambda_{m c}$ & truncnormal & 1.200 & 0.050 & 1.020 & 0.028 & 1.021 & 0.029 & & \\
\hline Markup.imported invest. & $\lambda_{m i}$ & truncnormal & 1.200 & 0.050 & 1.137 & 0.051 & 1.154 & 0.049 & & \\
\hline Investment adj. cost & $\tilde{S}^{\prime \prime}$ & normal & 7.694 & 1.500 & 7.951 & 1.295 & 7.684 & 1.261 & & \\
\hline Habit formation & $b$ & beta & 0.650 & 0.100 & 0.626 & 0.044 & 0.728 & 0.035 & & \\
\hline Subst. elasticity invest. & $\eta_{i}$ & invgamma & 1.500 & 4.0 & 1.239 & 0.031 & 1.238 & 0.030 & & \\
\hline Subst. elasticity foreign & $\eta_{f}$ & invgamma & 1.500 & 4.0 & 1.577 & 0.204 & 1.794 & 0.318 & & \\
\hline Risk premium & $\tilde{\phi}$ & invgamma & 0.010 & 2.0 & 0.038 & 0.026 & 0.144 & 0.068 & & \\
\hline UIP modification & $\tilde{\phi}_{s}$ & beta & 0.500 & 0.15 & 0.493 & 0.067 & 0.488 & 0.029 & & \\
\hline Unit root tech. shock & $\rho_{\mu_{z}}$ & beta & 0.750 & 0.100 & 0.790 & 0.065 & 0.765 & 0.072 & & \\
\hline Stationary tech. shock & $\rho_{\varepsilon}$ & beta & 0.750 & 0.100 & 0.966 & 0.006 & 0.968 & 0.005 & & \\
\hline Invest. spec. tech shock & $\rho_{\Upsilon}$ & beta & 0.750 & 0.100 & 0.750 & 0.077 & 0.719 & 0.067 & & \\
\hline Asymmetric tech. shock & $\rho_{\tilde{\phi}}$ & beta & 0.750 & 0.100 & 0.852 & 0.059 & 0.885 & 0.041 & & \\
\hline Consumption pref. shock & $\rho_{\zeta_{c}}$ & beta & 0.750 & 0.100 & 0.919 & 0.034 & 0.881 & 0.038 & & \\
\hline Labour supply shock & $\rho_{\zeta_{h}}$ & beta & 0.750 & 0.100 & 0.382 & 0.082 & 0.282 & 0.064 & & \\
\hline Risk premium shock & $\rho_{\tilde{z}^{*}}$ & beta & 0.750 & 0.100 & 0.722 & 0.052 & 0.736 & 0.058 & & \\
\hline Unit root tech. shock & $\sigma_{\mu_{z}}$ & invgamma & 0.200 & 2.0 & 0.127 & 0.025 & 0.201 & 0.039 & & \\
\hline Stationary tech. shock & $\sigma_{\varepsilon}$ & invgamma & 0.700 & 2.0 & 0.457 & 0.051 & 0.516 & 0.054 & & \\
\hline Invest. spec. tech. shock & $\sigma_{\Upsilon}$ & invgamma & 0.200 & 2.0 & 0.441 & 0.069 & 0.470 & 0.065 & & \\
\hline Asymmetric tech. shock & $\epsilon_{\tilde{z}^{*}}$ & invgamma & 0.400 & 2.0 & 0.199 & 0.030 & 0.203 & 0.031 & & \\
\hline Consumption pref. shock & $\tilde{\sigma_{\zeta_{c}}}$ & invgamma & 0.200 & 2.0 & 0.177 & 0.035 & 0.192 & 0.031 & & \\
\hline Labour supply shock & $\sigma_{\zeta_{h}}$ & invgamma & 1.000 & 2.0 & 0.470 & 0.051 & 0.511 & 0.053 & & \\
\hline Risk premium shock & $\sigma_{\tilde{\phi}}$ & invgamma & 0.050 & 2.0 & 0.454 & 0.157 & 0.519 & 0.067 & & \\
\hline Domestic markup shock & $\sigma_{\lambda_{d}}$ & invgamma & 1.000 & 2.0 & 0.656 & 0.064 & 0.667 & 0.068 & & \\
\hline Imp. cons. markup shock & $\sigma_{\lambda_{m c}}$ & invgamma & 1.000 & 2.0 & 0.838 & 0.081 & 0.841 & 0.084 & & \\
\hline Imp. invest. markup shock & $\sigma_{\lambda_{m i}}$ & invgamma & 1.000 & 2.0 & 1.604 & 0.159 & 1.661 & 0.169 & & \\
\hline Export markup shock & $\sigma_{\lambda_{x}}$ & invgamma & 1.000 & 2.0 & 0.753 & 0.115 & 0.695 & 0.122 & & \\
\hline Interest rate smoothing & $\rho_{R 1}$ & beta & 0.800 & 0.050 & 0.912 & 0.019 & 0.900 & 0.023 & & \\
\hline Inflation response & $r_{\pi 1}$ & truncnormal & 1.700 & 0.100 & 1.676 & 0.100 & 1.687 & 0.100 & & \\
\hline Diff. infl response & $r_{\Delta \pi 1}$ & normal & 0.300 & 0.100 & 0.210 & 0.052 & 0.208 & 0.053 & & \\
\hline Real exch. rate response & $r_{x 1}$ & normal & 0.000 & 0.050 & -0.042 & 0.032 & -0.053 & 0.036 & & \\
\hline Output response & $r_{y 1}$ & normal & 0.125 & 0.050 & 0.100 & 0.042 & 0.082 & 0.043 & & \\
\hline Diff. output response & $r_{\Delta y 1}$ & normal & 0.063 & 0.050 & 0.125 & 0.043 & 0.133 & 0.042 & & \\
\hline Monetary policy shock & $\sigma_{R 1}$ & invgamma & 0.150 & 2.0 & 0.465 & 0.108 & 0.647 & 0.198 & & \\
\hline Inflation target shock & $\sigma_{\bar{\pi}^{c} 1}$ & invgamma & 0.050 & 2.0 & 0.372 & 0.061 & 0.360 & 0.059 & & \\
\hline Interest rate smoothing 2 & $\rho_{R 2}$ & beta & 0.800 & 0.050 & 0.882 & 0.019 & & & & \\
\hline Inflation response 2 & $r_{\pi 2}$ & truncnormal & 1.700 & 0.100 & 1.697 & 0.097 & & & & \\
\hline Diff. infl response 2 & $r_{\Delta \pi 2}$ & normal & 0.300 & 0.100 & 0.132 & 0.024 & & & & \\
\hline Real exch. rate response 2 & $r_{x 2}$ & normal & 0.000 & 0.050 & -0.058 & 0.029 & & & & \\
\hline Output response 2 & $r_{y 2}$ & normal & 0.125 & 0.050 & 0.081 & 0.040 & & & & \\
\hline Diff. output response 2 & $r_{\Delta y 2}$ & normal & 0.063 & 0.050 & 0.100 & 0.012 & & & & \\
\hline Monetary policy shock 2 & $\sigma_{R 2}$ & invgamma & 0.150 & 2.0 & 0.135 & 0.029 & & & & \\
\hline Inflation target shock 2 & $\sigma_{\bar{\pi}^{c} 2}$ & invgamma & 0.050 & 2.0 & 0.081 & 0.037 & & & & \\
\hline Output stabilization & $\lambda_{y}$ & truncnormal & 0.5 & 100.0 & & & 1.091 & 0.526 & 1.102 & 0.224 \\
\hline Interest rate smoothing & $\lambda_{\Delta i}$ & truncnormal & 0.2 & 100.0 & & & 0.476 & 0.191 & 0.369 & 0.061 \\
\hline Log marg likelihood laplac & & & & & -2 & 56 & $\overline{-2}$ & 5 & & \\
\hline
\end{tabular}


There are two important facts to note in the first two posterior distributions. First, it is clear that the version of the model where policy is characterized with the simple instrument rule with an exogenous policy shock is a better characterization of how the Riksbank has conducted monetary policy during the inflation-targeting period. The difference between log marginal likelihoods is almost 23 in favor of the model with the instrument rule compared to the model with optimal policy. In terms of Bayesian posterior odds, this is overwhelming evidence against the loss-function characterization of the Riksbank's past policy behavior. However, this result crucially depends on the assumption that the simple instrument rule includes a policy shock (control error) and that the optimal policy rule does not. If we follow Wolden Bache, Brubakk, and Maih [38] and treat the two cases symmetrically by not including a policy shock in the simple rule during the inflation targeting period, that is, we impose $\sigma_{R 2}=0$, then the log marginal likelihood falls to -2654.5 , which is almost the same as for the optimal policy, implying that optimal policy fits the data equally well in this case. Alternatively, we can treat the two cases symmetrically by including a shock in the optimal policy rule. This improves the fit of optimal policy, but the log marginal likelihood (-2636.8) is then still lower than the log marginal likelihood for the simple instrument rule with a policy shock in table 3.1. Hence, for the particular sample period in question, with policy shocks in both rules the simple instrument rule offers a slightly better characterization of monetary policy. Compared to optimal policy the Bayesian posterior odds speak clearly in favor of the simple instrument rule, but in practice we have seen that log marginal likelihood differences (Laplace approximation) of these magnitudes do not necessarily generate very large discrepancies in terms of the forecasting accuracy, see ALLV [3] and Adolfson, Lindé and Villani [7]. Thus, the improvement in fit relative to optimal policy is moderate.

Second, perhaps more relevant for our purpose, the non-policy parameters of the model are fairly invariant to the specification of how monetary policy has been conducted during the inflationtargeting period. This is also true for the non-policy parameters of the model with the simple instrument rule without the policy shock. ${ }^{17}$

One way to assess the quantitative importance of the parameter differences between the instrument rule and the loss function (columns "Simple inst rule" and "Loss function") is to calibrate all parameters except the coefficients in the loss function to the estimates obtained in the simple rule specification of the model, and then reestimate the coefficients in the loss function conditional on

\footnotetext{
17 It should be noted that data are informative about the parameters as the posteriors are often different, and more concentrated, than the prior distributions. Moreover, Adolfson and Lindé [6] use Monte Carlo methods to study identification in a very similar model, and find that while a few parameters are weakly identified in small samples, all parameters are unbiased and consistent.
} 
these parameters. If the loss function parameters are similar, we can conjecture that the differences in deep parameters are quantitatively unimportant. The result of this experiment is reported in the last column in table 3.1 labeled "Loss fn params", and, as conjectured, the resulting loss function parameters are very similar to the ones obtained when estimating all parameters jointly. We interpret this result as support for our assumption that the non-policy parameters are unaffected by the alternative assumptions about the conduct of monetary policy we consider below.

In the subsequent analysis we use the posterior-mode estimates of the non-policy parameters for the model with the simple instrument rule. In most cases, the model with the simple instrument rule is also used to generate the (partly) unobserved state variables. For consistency reasons, the associated estimated loss function parameters $\lambda_{y}=1.102$ and $\lambda_{\Delta i}=0.369$ are therefore used in the analysis below.

\section{Monetary policy and the transmission of shocks}

According to the estimated model, shocks to total factor productivity play a dominant role in explaining business cycle variations in Sweden, as these shocks can explain the negative correlation between GDP growth and CPI inflation in our sample. In Adolfson, Laséen, Lindé and Svensson [2], we show that stationary technology shocks are the single most important driver of output fluctuations around trend. To interpret and understand the development of the Swedish economy, it is therefore of key importance to analyze and understand the effects of this type of technology shock.

To illustrate how optimal policy projections are affected by which output measure the central bank tries to stabilize we therefore start by looking at impulse response functions to a stationary technology shock. Although this type of technology shock $\left(\varepsilon_{t}\right)$ is estimated to be quite persistent $\left(\rho_{\varepsilon}=0.966\right)$ it does not affect trend output in the model (which by definition is only influenced by the permanent technology shock, $\mu_{z}$ ). In contrast, the output level under flexible prices and wages, flexprice potential output, increases with the shock. Abstracting from the policy response to the shock this means that the trend- and flexprice-output gaps, by definition, will behave quite differently following this shock.

Figure 4.1 shows impulse response functions to a positive (one-standard deviation) stationary technology shock under the instrument rule and under optimal policy with different output gaps. The plots show deviations from trend, where by trend we mean the steady state. Output thus equals the trend output gap. The real interest rate is defined as the instrument rate less 1-quarter- 
Figure 4.1: Impulse responses to a (one-standard deviation) stationary technology shock under optimal policy for different output gaps and under the instrument rule
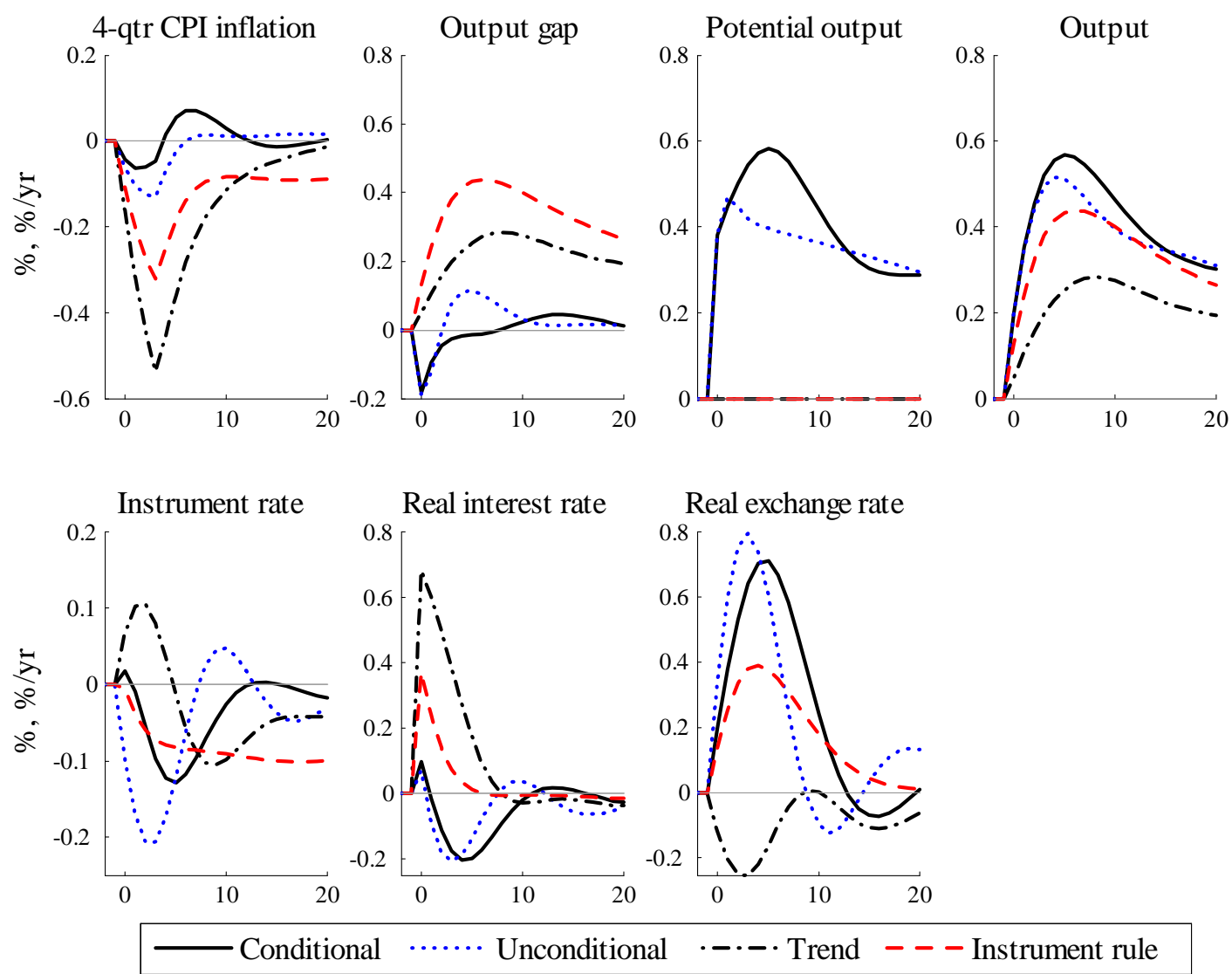

ahead CPI inflation expectations. All variables are measured in percent or percent per year. The impulse occurs in quarter 0 . Before quarter 0 , the economy is in the steady state with $X_{t}=0$ and $\Xi_{t-1}=0$ for $t \leq 0$ and $x_{t}=0$ and $i_{t}=0$ for $t \leq-1$.

The dashed curves show the impulse responses when policy follows the instrument rule (which responds to the trend output gap). For the central bank, the stationary technology shock creates a trade-off between balancing the induced decline in inflation and the improvement in the (trend) output gap. Since the shock is very persistent $\left(\rho_{\varepsilon}=0.966\right)$ this trade-off will last for many quarters, and it takes time before inflation can be brought back to target. The instrument rule keeps the nominal interest rate below the steady state for the 20 periods plotted and longer. The real interest increases and remains positive for about a year, whereas there is a real depreciation of the currency. The result is a relatively large positive output gap and a negative inflation gap between inflation and the target. These gaps remain for a long time. The instrument rule is obviously not successful 
in closing these gaps with the time-period plotted.

The dashed-dotted curves show the responses under optimal policy when the trend output gap enters the loss function of the central bank. The weights in the loss function, as for all responses under optimal policy in this figure, are $\lambda_{y}=1.1$, and $\lambda_{\Delta i}=0.37$, the estimated weights in table 3.1 when the non-policy parameters are kept at their posterior mode obtained under the instrument rule. We see that this optimal policy stabilizes inflation and the output gap more effectively over time than the instrument rule, although optimal policy (with the trend output gap in the loss function) initially allows for a larger fall in CPI inflation. This requires initially tighter monetary policy than the instrument-rule, as demonstrated by initially higher nominal and real interest rates and a real appreciation of the currency.

The solid curves show the impulse responses under optimal policy when the output gap in the loss function is the conditional output gap. Hence, potential output plotted in the figure is conditional potential output, and the output gap plotted is the conditional output gap. We see that this optimal policy successfully stabilizes 4-quarter CPI inflation around the inflation target. It also successfully stabilizes the output gap, and we see that the conditional output gap is much smaller than the trend output gap and initially even negative. Due to sticky prices and wages, the stationary technology shock affects potential output quicker than actual output and the flexprice (conditional and unconditional) output gaps are therefore initially negative, whereas the trend output gap is positive. This implies that the interest rate responses will differ depending on which output gap the central bank tries to stabilize. With the flexprice output gap in its loss function, the central bank does not face an unfavorable trade-off between stabilizing inflation and output after a technology shock. Optimal policy takes into account that conditional potential output is high because productivity is temporarily high and therefore allows for more expansionary policy (as shown by lower nominal and real interest rates) and higher actual output than when the trend output gap is the target variable or when the instrument rule is followed. This in effect implies that inflation can be stabilized much quicker than for policy with the trend output gap, even though the weights in the loss function are the same in the two cases.

That the instrument rule is specified in terms of the trend output gap (rather than, for instance, the conditional output gap) is also one of the main reasons why the instrument rule does not bring inflation quickly back to target in this particular situation. Had the rule instead been specified with a stronger inflation response than the estimated one or using a response to the conditional or unconditional output gap, the inefficient trade-off between inflation and output stabilization would 
be less pronounced.

The dotted curves in figure 4.1 show the impulse responses when the output gap in the loss function is the unconditional output gap. Comparing with the impulse responses with the conditional output gap in the loss function, we see that potential output levels differ from period 1 and onwards. This occurs because the conditional and unconditional potential output levels are computed from different predetermined variables (those in the actual sticky-price economy, and those in the hypothetical economy with flexible prices and wages in the past and present, respectively). Thus, unconditional potential output is independent of policy, whereas conditional potential output depends on policy through the endogenous predetermined variables. When the shock hits the economy in quarter 0 , the two output-gap definitions will be equal (since the economy by assumption starts out in steady state in quarter -1 , which is the same for both the actual economy and the hypothetical flexprice economy), but in quarter 1 they will diverge. The predetermined variables in quarter 1 in the sticky-price economy will differ from those in the flexprice economy because the forward-looking variables and the instrument rate in quarter 0 will differ between the sticky-price and the flexprice economies. Even if no new innovations have occurred between quarter 0 and quarter $t$, the levels of the predetermined variables used for computing the two potential output levels will thus differ. Since actual output and conditional potential output share the same predetermined variables in each period, we would expect the conditional output gap will normally be smaller than the unconditional output gap.

\section{Optimal policy projections and the Great Recession}

Having estimated the model and obtained an understanding of the role of different monetary policy assumptions can play for the propagation of shocks, we now turn to a discussion about how to compute optimal policy projections with the model. We also consider an application to the Great Recession in the world economy that was initiated during 2008.

\subsection{Information and data}

To calculate the optimal policy projection for a policy maker in period(quarter) $t$ we assume the following. The information set, $\mathcal{I}_{t}$, in the beginning of period $t$, just after the instrument setting for quarter $t$ has been announced, is specified as

$$
\mathcal{I}_{t} \equiv\left\{i_{t}, Z_{t-1}, Z_{t-2}, \ldots\right\}
$$


where $Z_{t}$ is the $n_{Z}$-vector of observable variables that satisfies the measurement equation,

$$
Z_{t}=\bar{D}\left[\begin{array}{c}
X_{t} \\
x_{t} \\
i_{t}
\end{array}\right]+\eta_{t}
$$

and where $\bar{D}$ is a given matrix and $\eta_{t}$ is an $n_{Z}$-vector of i.i.d. period- $t$ measurement errors with distribution $N\left(0, \Sigma_{\eta}\right)$.

For the monetary-policy decision at the beginning of quarter $t$, the matrices $A, B, C$, and $H$ as well as the state vectors, denoted $X_{t-\tau \mid t}, x_{t-\tau \mid t}, C \varepsilon_{t-\tau \mid t}$, and $\eta_{t-\tau \mid t}$ for $\tau \geq 1$, are formed by the posterior mode estimates in table 3.1 . We also specify the estimate of $X_{t}$, denoted $X_{t \mid t}$, as

$$
X_{t \mid t}=A_{11} X_{t-1 \mid t}+A_{12} x_{t-1 \mid t}+B_{1} i_{t-1 \mid t}
$$

where the estimated shocks $C \varepsilon_{t \mid t}=0$ since $Z_{t}$ is not in the information set $\mathcal{I}_{t}{ }^{18}$

With respect to projections in period $t$, we regard the matrices $A, B, C$, and $H$ as certain and known. Then we can rely on certainty equivalence - under which conditional means of the relevant variables are sufficient for determining the optimal policy - and compute the optimal projections accordingly. ${ }^{19}$

\subsection{The projection model and optimal projections}

Let $y^{t} \equiv\left\{y_{t+\tau, t}\right\}_{\tau=0}^{\infty}$ denote a projection in period $t$ for any variable $y_{t}$, a mean forecast conditional on information in period $t$. The projection model for the projections $\left(X^{t}, x^{t}, i^{t}, Y^{t}\right)$ in period $t$ is

$$
\begin{aligned}
{\left[\begin{array}{c}
X_{t+\tau+1, t} \\
H x_{t+\tau+1, t}
\end{array}\right] } & =A\left[\begin{array}{c}
X_{t+\tau, t} \\
x_{t+\tau, t}
\end{array}\right]+B i_{t+\tau, t}, \\
Y_{t+\tau, t} & =D\left[\begin{array}{c}
X_{t+\tau, t} \\
x_{t+\tau, t} \\
i_{t+\tau, t}
\end{array}\right]
\end{aligned}
$$

for $\tau \geq 0$, where

$$
X_{t, t}=X_{t \mid t}
$$

18 Thus, the estimated/expected shock $C \varepsilon_{t+\tau \mid t}$ and $\eta_{t+\tau \mid t}$ for $\tau \geq 0$ are zero, whereas the estimated shocks $C \varepsilon_{t-\tau \mid t}$ and $\eta_{t-\tau \mid t}$ for $\tau \geq 1$ are given by $C \varepsilon_{t-\tau \mid t}=X_{t-\tau \mid t}-A_{11} X_{t-\tau-1 \mid t}-A_{12} x_{t-\tau-1 \mid t}-B_{1} i_{t-\tau-1}$ and $\eta_{t-\tau \mid t}=$ $Z_{t-\tau}-\bar{D}\left(X_{t-\tau \mid t}^{\prime}, x_{t-\tau \mid t}^{\prime}, i_{t-\tau}\right)^{\prime}$, and are normally nonzero.

19 It should be noted that the setup here differs compared to what was used in, for example, ALLV [3] and [5], which examine forecasts using an instrument rule. There uncertainty about both parameters, the current state of the economy, the sequence of future shocks as well as the measurement errors were allowed for (see Adolfson, Lindé and Villani [7] for a description). However, this uncertainty is additive so certainty equivalence holds. Also our timing convention for the projections differs. In ALLV [3], [5], and [7] it is assumed that the projections are carried out at the end of period $t$ (using the estimated instrument rule). That is, $Z_{t}$ is observed and considered to be known at the time of the projection in ALLV [3], [5], and [7]. 
where $X_{t \mid t}$ is given by (5.1). Thus, we let ", $t$ " and " $t$ " in subindices refer to projections and estimates (rational expectations) in the beginning of period $t$, respectively. The reason for this separate notation for the projections is that they are conceptually distinct from the equilibrium rational expectations and include possible hypothetical projections contemplated by the central bank during its decision process. The feasible set of projections for given $X_{t \mid t}$ is the set of projections that satisfy (5.2)-(5.4).

The policy problem in period $t$ is to determine the optimal projection in period $t$, denoted $\left(\check{X}^{t}, \check{x}^{t}, \check{i}^{t}, \check{Y}^{t}\right)$. The optimal projection is the projection that minimizes the intertemporal loss function,

$$
\sum_{\tau=0}^{\infty} \delta^{\tau} L_{t+\tau, t},
$$

where the period loss, $L_{t+\tau, t}$, is specified as

$$
L_{t+\tau, t}=Y_{t+\tau, t}{ }^{\prime} W Y_{t+\tau, t},
$$

where $W$ is symmetric positive semidefinite matrix with diagonal $\left(1, \lambda_{y}, \lambda_{\Delta i}\right)^{\prime}$. The minimization is subject to the projection being in the feasible set of projections for given $X_{t \mid t} \cdot{ }^{20}$

When the policy problem is formulated in terms of projections, we can allow $0<\delta \leq 1$, since the above infinite sum will normally converge also for $\delta=1$. The optimization is done under commitment in a timeless perspective (Woodford [39]). The optimization results in a set of firstorder conditions, which combined with the model equations, (2.21), yields a system of difference equations (see Söderlind [28] and Svensson [30]) that can be solved with several alternative numerical algorithms (see section 2.6 for references). ${ }^{21}$

Under the assumption of optimization under commitment in a timeless perspective, one way to describe the optimal projection is by the following difference equations,

$$
\begin{aligned}
{\left[\begin{array}{c}
\check{x}_{t+\tau, t} \\
\check{i}_{t+\tau, t}
\end{array}\right] } & =F\left[\begin{array}{c}
\check{X}_{t+\tau, t} \\
\Xi_{t+\tau-1, t}
\end{array}\right], \\
{\left[\begin{array}{c}
\check{X}_{t+\tau+1, t} \\
\Xi_{t+\tau, t}
\end{array}\right] } & =M\left[\begin{array}{c}
\check{X}_{t+\tau, t} \\
\Xi_{t+\tau-1, t}
\end{array}\right],
\end{aligned}
$$

for $\tau \geq 0$, where $\check{X}_{t, t}=X_{t \mid t}$. The matrices $F$ and $M$ depend on $A, B, H, D, W$, and $\delta$, but are independent of $C$. The independence of $C$ demonstrates the certainty equivalence of the projections. The $n_{X}$-vector $\Xi_{t+\tau, t}$ consists of the Lagrange multipliers of the lower block of (5.2), the block

\footnotetext{
${ }^{20}$ Policy projections when monetary policy is characterized by a simple instrument rule are described in appendix B.

21 As discussed in Woodford [39] and Svensson [30] and [31], optimization under commitment in a timeless perspective allows optimal policy that is consistent over time. Svensson [31] also discusses optimal projections under discretion.
} 
determining the projection of the forward-looking variables. We assume that the optimization is under commitment in a timeless perspective, so that the initial Lagrange multiplier, $\Xi_{t-1, t}$, is nonzero. Commitment is thus considered having occurred some time in the past, and more precisely we assume policy has been optimal since the start of the inflation targeting in 1993:1. ${ }^{22}$

\subsection{An application to the Great Recession}

Next, we use the model to interpret the future economic development in Sweden for a policy maker standing in 2008:3. This period is especially interesting to analyze since the world economy were just about to enter a deep recession in the following quarters.

Figure 5.1 show projections from Ramses using data up to and including 2008:2, for 10 key variables: foreign output, foreign annualized 1-quarter CPI inflation, foreign interest rate, the real exchange rate, 4-quarter CPI inflation, the output gap, the instrument rate, the real interest rate (the instrument rate less 1-quarter-ahead CPI inflation expectations), output and potential output. The plots show deviations from steady state. The solid vertical line marks 2008:3, which is quarter 0 in the figure. The curves to the left of the line shows the history of actual data up to and including 2008:2, which is quarter -1 in the figure. The state in 2008:2, and its history, is estimated using policy with the instrument rule.

The solid curves to the right of the solid vertical line show the projections for a policy maker following the estimated instrument rule. We see that Ramses' VAR-model for the three foreign variables did not forecast the large drop in the world economy that occurred in the next few quarters after 2008:3, following the turbulence in the financial markets. In reality, world output diminished by almost 4 percent in the next three quarters and world inflation approached 0 percent. Given the VAR-model's counterfactual view of the foreign economy, Ramses projected Swedish CPI inflation to be close to 2 percent and output to be less than 0.5 percent below its trend level. Ex post, we know Swedish GDP decreased by almost 6 percent in the next year and consumer prices actually declined.

We know from VAR evidence that international spillover effects to small open economies are generally large. Lindé [19] shows, using a block exogenity assumption in a VAR model on Swedish data, that foreign shocks account for around 50 percent of the fluctuations around trend in Swedish output and domestic inflation. Can then the substantial drop in the world economy explain the economic development in Sweden during the financial crisis? To analyze this we compute a forecast

\footnotetext{
${ }^{22}$ See appendix B.3 for a discussion about alternative methods to calculate the initial Lagrange multipliers.
} 
with Ramses that is conditional upon the decline in foreign output during 2008:4 - 2009:2. After those three quarters the forecast is endogenously determined by the model, which is marked by a dashed vertical line. It is assumed that the agents in the model fully anticipate the path of foreign output during 2008:4 - 2009:2. The expectations in the model are thus consistent with the conditional path of foreign output. We use the method in Laséen and Svensson [18] to calculate how large time-varying intercepts in the VAR equation for foreign output are needed to replicate the drop in foreign output. Foreign inflation and the foreign interest rate is then determined endogenously within the foreign VAR model.

The dashed curves in figure 5.1 show this conditional projection when policy follows the estimated instrument rule. The cumulative drop of about 3.7 percent in world output implies that world inflation drops 1 percent below steady state and that the world interest rate almost hits the zero lower bound. The steady state level of the nominal interest rate in both Sweden and the rest of the world is assumed to be 4.25 percent, and, as stated above, the plots show deviations from steady state. The substantial fall in foreign output implies less demand for Swedish export goods, and domestic output drops below trend by about 1.5 percent. We see that the spillover to Swedish production is approximately 50 percent of the drop in the world economy. However, CPI inflation in Sweden decreases by more than the decline in the world economy. From figure 5.1 we also see that the instrument rule implies that the Swedish interest rate is lowered by about 2 percentage points below its steady state level. Since the foreign interest rate falls by more, this implies that the nominal (not depicted) and real (depicted) exchange rate appreciates, due to the UIP condition in the model. In reality we saw a large flight from the Swedish krona, however.

To account for the large depreciation of the real exchange rate, the model needs risk premium shocks that can capture the deviations from interest rate parity. In reality, substantial declines in investment and exports also occurred. To capture all components in the GDP identity (and thereby describe the entire fall in Swedish GDP), the model additionally requires shocks to investment technology and the export markup. The large fall in foreign output can thus not alone explain all aspects of the development of the Swedish economy during the financial crisis.

There are several reasons for why the model scenario under consideration cannot fully capture the fall in domestic GDP that actually occurred. The scenario above, with a decline in foreign output only, works through the trade and real exchange rate channels of the model. In reality, the recession was created in the financial sector which caused the spread between inter-bank rates and the instrument rate to increase dramatically. As in most DSGE models, Ramses lacks such a 
Figure 5.1: Projections in 2008:3 for the instrument rule
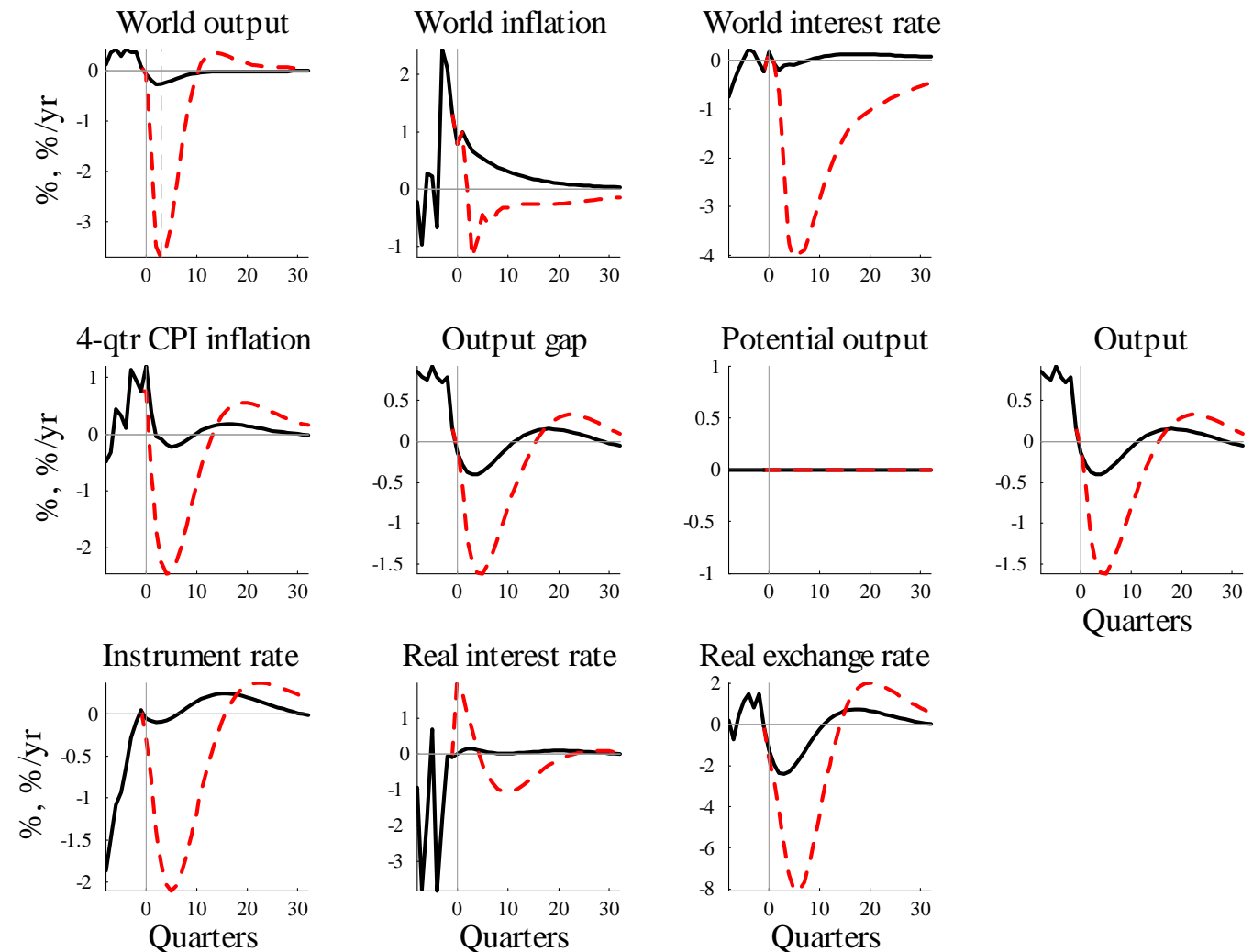

Endogenous projection

-- Conditional projection

financial sector that includes a financing premium which could have further dampened domestic GDP. ${ }^{23}$ If we would have been able to consider both shocks simultaneously, this would have caused the zero bound on nominal interest rates to bind for Sweden's most important trading partners and in all likelihood also for the Swedish economy. This channel, per se, would have amplified the fall in domestic output even further.

Finally, we assess how the projections during the financial crisis could have been affected by alternative monetary policies. Depending on the state of the economy (and thus the current size of the shocks that persistently die out over the projection horizon), the policy assumption of which output measure to stabilize can matter quite a bit for the projections, as shown in section 4 . In figure 5.2 we therefore compare projections with the instrument rule and projections with policy for different output gaps in the loss function. In all the optimal policy projections in this figure, we

\footnotetext{
${ }^{23}$ Christiano, Trabandt and Walentin [12] estimate a similar model to ours extended with financial frictions on Swedish data and find that shocks stemming from the financial sector indeed contributed significantly to the contraction in output during 2008-2009. A variant of their model has recently replaced the version of Ramses we consider in the policy process at the Riksbank.
} 
Figure 5.2: Difference between unconditional and conditional projections in 2008:3 for optimal policy with different output gaps $\left(\lambda_{y}=1.1, \lambda_{\Delta i}=0.37\right)$
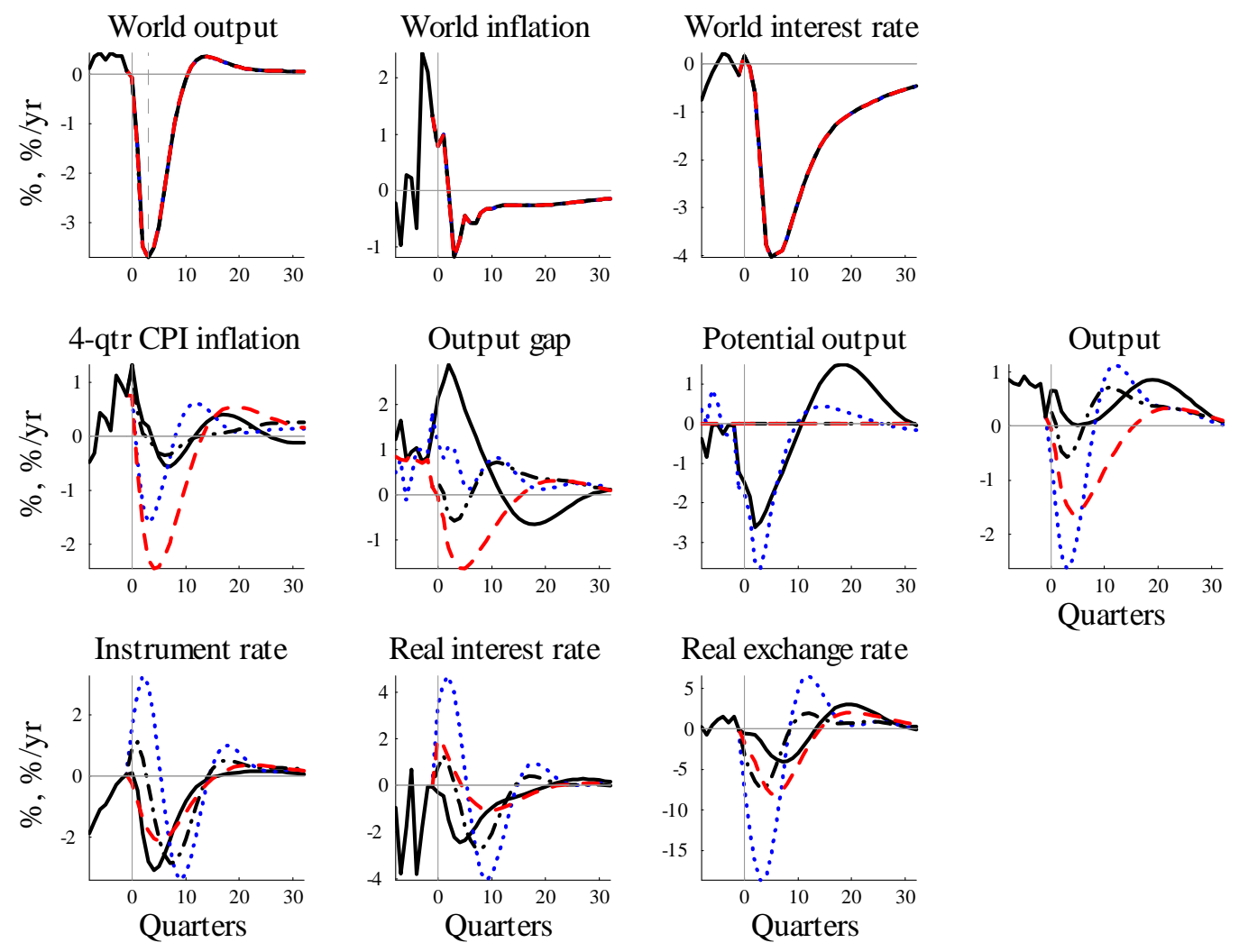

- Conditional gap $\quad \cdots \cdots$ Unconditional gap $\quad \cdots-\cdots-$ Trend gap $\quad-\quad-$ Instrument rule

assume commitment in a timeless perspective and compute the initial vector of Lagrange multipliers for the equations for the forward-looking variables $\left(\Xi_{-1}\right)$ under the assumption that policy during the inflation-targeting period has been optimal (see appendix B.3). ${ }^{24}$ As in figure 5.1 we condition all the projections on the decline in foreign output during the first three quarters after 2008:3.

The dashed curves in figure 5.2 reprints the conditional projections from figure 5.1 where policy follows the instrument rule. The solid curves show optimal policy projections with the conditional output gap in the loss function. The dotted curves show the optimal policy projections when the output gap in the loss function is the unconditional output gap (which is computed using equation (C.7) with flexible prices from 1993:1 and onwards to form the state vector under flexible prices). The dashed-dotted curves show the optimal policy projections with the trend output gap in the loss function.

In figure 5.2, we see that 4-quarter CPI-inflation and the output gap falls quite a bit when

\footnotetext{
${ }^{24}$ It should, however, be noted that the results do not change much to setting the Lagrange multipliers to zero.
} 
policy follows the instrument rule. Optimal policy, with the trend output gap in the loss function, is shown with the dash-dotted curves. It is able to stabilize both inflation and the output gap much better. With the instrument rule's slow adjustment of the instrument rate, the real interest rate initially increases because inflation falls so quickly and is then followed by a compensating modest fall in the real interest rate. Optimal policy initially increases the real interest rate less and then lowers the real interest rate substantially. This implies substantially more expansionary policy and succeeds in preventing large falls in both CPI inflation and output. In spite of the non-negligible weight on instrument-rate smoothing, optimal policy allows the instrument rate to first increase and then fall substantially, a much more effective policy than the instrument rule's smooth fall and rise of the instrument rate. It is important to understand that the initial increase in the nominal instrument rate for the loss function with the trend gap is driven by the initial state of the economy. Had the economy been in steady state when the negative foreign demand shocks hit the economy, the instrument rate for the loss function with the trend gap would have been lowered directly.

Optimal policy with the unconditional output gap in the loss function and potential output given by unconditional flexible-price output is shown with the dotted curves. The fall in world output and the other foreign shocks imply a large fall in potential output. Optimal policy results in a small positive output gap. This requires a large fall in output, which requires contractionary monetary policy in the form of a high real interest rate and a real appreciation of the currency. This results in an intermediate fall in CPI-inflation.

Optimal policy with the conditional output gap in the loss function and potential output given by conditional flexible-price output is shown with the solid curves. The shocks from the world economy results in a fall and then a rise in potential output. Optimal policy results in first a positive and then a negative output gap, corresponding to positive output falling to the steadystate level and then rising above. CPI inflation falls modestly below target and then rises above. This requires expansionary monetary policy, with a significant fall in the real interest rate and initially much smaller real appreciation of the currency than the other policies.

Clearly, it matters quite a bit for optimal policy what output gap enters the loss function, with different consequences for the dynamics of output and inflation and the optimal policy response. Some policies result in considerably more output and CPI stabilization than others. Clearly it is important to determine what potential-output definition is the most appropriate. 


\section{Conclusions}

In this paper, we have shown how to construct operational optimal policy projections in the Riksbank's model Ramses, a linear-quadratic open-economy DSGE model. By optimal policy projections we mean projections of the target variables and the instrument rate that minimize a loss function. We have illustrated the use and consequences of different output-gap concepts in the loss function and clarified the difference between output gaps relative to conditional potential output, trend output, and unconditional potential output, where conditional refers to the dependence on existing endogenous predetermined variables, such as the capital stock. When productivity is temporarily high, conditional potential output exceeds trend output. Then optimal policy projections in this case differ substantially depending on whether conditional or trend output gaps enter the loss function.

We have also illustrated how the model interpreted the economic development in Sweden with the Great Recession ahead in 2008:3, using different policy assumptions. We studied the direct impact of the fall in the world economy, but not the financial spillover that must have accounted for a large share of the Swedish output decline. An important challenge ahead for the profession is to develop DSGE models with elaborate financial frictions.

With the tools we have demonstrated, we believe optimal policy projections in Ramses and similar DSGE models can now be applied in real-time policy processes and provide policymakers with useful advice for their decisions - together with the usual input of detailed analysis and estimation of the initial state of the economy, policy simulations with historical policy reaction functions, other forecasting models, judgment, concerns about model uncertainty, and so forth. 


\section{Appendix}

\section{A. Ramses in some detail}

This appendix presents the loglinear approximation of the model. For a more detailed description of the complete model and the derivation of the loglinear approximation, see ALLV [4]. A hat denotes the deviation of a loglinearized variable from a steady-state level $\left(\hat{v}_{t} \equiv d v_{t} / v\right.$ for any variable $v_{t}$, where $v$ is the steady-state level), and delta denotes the log-difference of a variable $\left(\Delta v_{t} \equiv v_{t}-v_{t-1}\right.$ for any variable $v_{t}$ ). Since all real variables grow with the non-stationary technology shock $z_{t}$, we have to divide all quantities with the trend level of technology to make them stationary. We denote the resulting stationary variables by lower-case letters, that is, $c_{t}=C_{t} / z_{t}, \tilde{\imath}_{t}=I_{t} / z_{t}$ (we denote investment by $\tilde{\imath}_{t}$ to avoid confusion with the monetary-policy instrument $\left.i_{t}\right), k_{t+1}=K_{t} / z_{t}$ (capital-services), $\bar{k}_{t+1}=\bar{K}_{t+1} / z_{t}$ (physical capital stock), $\bar{w}_{t}=W_{t} /\left(P_{t} z_{t}\right)$ (real wage).

Inflation, $\hat{\pi}_{t}^{j}$, in the four sectors of firms $j \in\{d, \mathrm{mc}, \mathrm{mi}, x\}$ : domestic (production) (d), consumergoods import (mc), investment-goods import (mi), and export $(x)$, is determined from the Phillips curve

$$
\begin{aligned}
\xi_{j}\left(\hat{\pi}_{t}^{j}-\hat{\bar{\pi}}_{t}^{c}\right)= & \frac{\xi_{j} \beta}{1+\kappa_{j} \beta}\left(\hat{\pi}_{t+1 \mid t}^{j}-\rho_{\bar{\pi}^{c}} \widehat{\bar{\pi}}_{t}^{c}\right)+\frac{\xi_{j} \kappa_{j}}{1+\kappa_{j} \beta}\left(\hat{\pi}_{t-1}^{j}-\widehat{\bar{\pi}}_{t}^{c}\right) \\
& -\frac{\xi_{j} \kappa_{j} \beta\left(1-\rho_{\bar{\pi}^{c}}\right)}{1+\kappa_{j} \beta} \widehat{\bar{\pi}}_{t}^{c}+\frac{\left(1-\xi_{j}\right)\left(1-\beta \xi_{j}\right)}{1+\kappa_{j} \beta}\left(\widehat{\mathrm{mc}}_{t}^{j}+\hat{\lambda}_{t}^{j}\right),
\end{aligned}
$$

The firms' marginal costs, $\widehat{\mathrm{mc}}_{t}^{j}$, are defined as

$$
\begin{aligned}
\widehat{\mathrm{mc}}_{t}^{d} & \equiv \alpha\left(\hat{\mu}_{z t}+\hat{H}_{t}-\hat{k}_{t}\right)+\widehat{\bar{w}}_{t}+\hat{R}_{t}^{f}-\hat{\varepsilon}_{t}, \\
\widehat{\mathrm{mc}}_{t}^{\mathrm{mc}} & \equiv \hat{P}_{t}^{*}+\hat{S}_{t}-\hat{P}_{t}^{\mathrm{mc}} \equiv-\widehat{\mathrm{mc}}_{t}^{x}-\hat{\gamma}_{t}^{x *}-\hat{\gamma}_{t}^{\mathrm{mc} d}, \\
\widehat{\mathrm{mc}}_{t}^{\mathrm{mi}} & \equiv \hat{P}_{t}^{*}+\hat{S}_{t}-\hat{P}_{t}^{\mathrm{mi}} \equiv-\widehat{\mathrm{mc}}_{t}^{x}-\hat{\gamma}_{t}^{x *}-\hat{\gamma}_{t}^{\mathrm{mi} d} \\
\widehat{\mathrm{mc}}_{t}^{x} & \equiv \hat{P}_{t}^{d}-\hat{S}_{t}-\hat{P}_{t}^{x} \equiv \widehat{\mathrm{mc}}_{t-1}^{x}+\hat{\pi}_{t}-\hat{\pi}_{t}^{x}-\Delta \hat{S}_{t},
\end{aligned}
$$

respectively; where $\hat{R}_{t}^{f}$ denotes the effective nominal interest rate paid by the firms,

$$
\hat{R}_{t}^{f}=\frac{\nu R}{v(R-1)+1} \hat{R}_{t-1}+\frac{\nu(R-1)}{v(R-1)+1} \hat{\nu}_{t}
$$

where $\hat{\nu}_{t}$ is a shock to the fraction of firms that has to finance their wage bill in advance (throughout 
we set $\nu=1)$. Furthermore, $\hat{\gamma}_{t}^{x *}, \hat{\gamma}_{t}^{\mathrm{mc} d}, \hat{\gamma}_{t}^{\mathrm{mi} d}$, and $\hat{\gamma}_{t}^{f}$ are relative prices defined as

$$
\begin{aligned}
\hat{\gamma}_{t}^{x *} & \equiv \hat{P}_{t}^{x}-\hat{P}_{t}^{*} \equiv \hat{\gamma}_{t-1}^{x *}+\hat{\pi}_{t}^{x}-\hat{\pi}_{t}^{*}, \\
\hat{\gamma}_{t}^{\mathrm{mc} d} & \equiv \hat{P}_{t}^{\mathrm{mc}}-\hat{P}_{t}^{d} \equiv \hat{\gamma}_{t-1}^{\mathrm{mc} d}+\hat{\pi}_{t}^{\mathrm{mc}}-\hat{\pi}_{t}^{d}, \\
\hat{\gamma}_{t}^{\mathrm{mid}} & \equiv \hat{P}_{t}^{\mathrm{mi}}-\hat{P}_{t}^{d} \equiv \hat{\gamma}_{t-1}^{\mathrm{mi} d}+\hat{\pi}_{t}^{\mathrm{mi}}-\hat{\pi}_{t}^{d} \\
\hat{\gamma}_{t}^{f} & \equiv \hat{P}_{t}^{d}-\hat{S}_{t}-\hat{P}_{t}^{*} \equiv \widehat{\mathrm{mc}}_{t}^{x}+\hat{\gamma}_{t}^{x *}
\end{aligned}
$$

CPI inflation, $\hat{\pi}_{t}^{c}$, satisfies

$$
\hat{\pi}_{t}^{c}=\left(1-\omega_{c}\right)\left(\gamma^{c d}\right)^{-\left(1-\eta_{c}\right)} \hat{\pi}_{t}^{d}+\omega_{c}\left(\gamma^{c \mathrm{mc}}\right)^{-\left(1-\eta_{c}\right)} \hat{\pi}_{t}^{\mathrm{mc}}
$$

The real-wage equation can be written

$$
\begin{aligned}
0= & b_{w} \xi_{w} \widehat{\bar{w}}_{t-1}+\left[\sigma_{L} \lambda_{w}-b_{w}\left(1+\beta \xi_{w}^{2}\right)\right] \widehat{\bar{w}}_{t}+b_{w} \beta \xi_{w} \widehat{\bar{w}}_{t+1 \mid t} \\
& -b_{w} \xi_{w}\left(\hat{\pi}_{t}^{d}-\widehat{\bar{\pi}}_{t}^{c}\right)+b_{w} \beta \xi_{w}\left(\hat{\pi}_{t+1}^{d}-\rho_{\bar{\pi}^{c}} \widehat{\bar{\pi}}_{t}^{c}\right) \\
& +b_{w} \xi_{w} \kappa_{w}\left(\hat{\pi}_{t-1}^{c}-\widehat{\bar{\pi}}_{t}^{c}\right)-b_{w} \beta \xi_{w} \kappa_{w}\left(\hat{\pi}_{t}^{c}-\rho_{\bar{\pi}^{c}} \widehat{\bar{\pi}}_{t}^{c}\right) \\
& +\left(1-\lambda_{w}\right) \hat{\psi}_{z t}-\left(1-\lambda_{w}\right) \sigma_{L} \hat{H}_{t} \\
& -\left(1-\lambda_{w}\right) \frac{\tau^{y}}{1-\tau^{y}} \hat{\tau}_{t}^{y}-\left(1-\lambda_{w}\right) \frac{\tau^{w}}{1+\tau^{w}} \hat{\tau}_{t}^{w}-\left(1-\lambda_{w}\right) \hat{\zeta}_{t}^{h}
\end{aligned}
$$

where

$$
b_{w} \equiv \frac{\lambda_{w} \sigma_{L}-\left(1-\lambda_{w}\right)}{\left(1-\beta \xi_{w}\right)\left(1-\xi_{w}\right)}
$$

$\hat{\psi}_{z t}$ denotes the marginal utility of income.

The Euler equation for consumption expenditures is,

$$
\begin{aligned}
0= & -b \beta \mu_{z} \hat{c}_{t+1 \mid t}+\left(\mu_{z}^{2}+b^{2} \beta\right) \hat{c}_{t}-b \mu_{z} \hat{c}_{t-1}+b \mu_{z}\left(\hat{\mu}_{z t}-\beta \hat{\mu}_{z, t+1 \mid t}\right) \\
& +\left(\mu_{z}-b \beta\right)\left(\mu_{z}-b\right) \hat{\psi}_{z t}+\frac{\tau^{c}}{1+\tau^{c}}\left(\mu_{z}-b \beta\right)\left(\mu_{z}-b\right) \hat{\tau}_{t}^{c} \\
& +\left(\mu_{z}-b \beta\right)\left(\mu_{z}-b\right) \hat{\gamma}_{t}^{c d}-\left(\mu_{z}-b\right)\left(\mu_{z} \hat{\zeta}_{t}^{c}-b \beta \hat{\zeta}_{t+1 \mid t}^{c}\right)
\end{aligned}
$$

where

$$
\hat{\gamma}_{t}^{c d} \equiv \hat{P}_{t}^{c}-\hat{P}_{t}^{d} \equiv \hat{\gamma}_{t-1}^{c d}+\hat{\pi}_{t}^{c}-\hat{\pi}_{t}^{d}
$$

denotes the relative price between consumption and domestically produced goods.

The household's first-order conditions with respect to investment $\tilde{\imath}_{t}$, the physical capital stock $\bar{k}_{t+1}$, and the utilization rate

$$
\hat{u}_{t} \equiv \hat{k}_{t}-\widehat{\bar{k}}_{t}
$$


are, in their loglinearized forms, given by

$$
\begin{gathered}
\hat{P}_{k t}+\hat{\Upsilon}_{t}-\hat{\gamma}_{t}^{i d}-\mu_{z}^{2} \tilde{S}^{\prime \prime}\left[\left(\widehat{\tilde{\imath}}_{t}-\widehat{\tilde{\imath}}_{t-1}\right)-\beta\left(\widehat{\tilde{\imath}}_{t+1 \mid t}-\widehat{\tilde{\imath}}_{t}\right)+\hat{\mu}_{z t}-\beta \hat{\mu}_{z, t+1 \mid t}\right]=0 \\
\hat{\psi}_{z t}+\hat{\mu}_{z, t+1 \mid t}-\hat{\psi}_{z, t+1 \mid t}-\frac{\beta(1-\delta)}{\mu_{z}} \hat{P}_{k, t+1 \mid t}+\hat{P}_{k t}-\frac{\mu_{z}-\beta(1-\delta)}{\mu_{z}} \hat{r}_{t+1 \mid t}^{k}+\frac{\tau^{k}}{1-\tau^{k}} \frac{\mu_{z}-\beta(1-\delta)}{\mu_{z}} \hat{\tau}_{t+1 \mid t}^{k}=0 \\
\hat{u}_{t}=\frac{1}{\sigma_{a}} \hat{r}_{t}^{k}-\frac{1}{\sigma_{a}} \frac{\tau^{k}}{\left(1-\tau^{k}\right)} \hat{\tau}_{t}^{k}
\end{gathered}
$$

where $P_{k t}$ is the price of capital goods in terms of domestic goods, $\delta$ is the depreciation rate, $\sigma_{a}$ is a parameter determining the capital utilization rate (here calibrated so that there is no variable capital utilization $\sigma_{a}=10^{6}$ ) and $\hat{r}_{t}^{k}$ denotes the log-linearized expression for the real rental rate of capital and satisfies

$$
\hat{r}_{t}^{k}=\hat{\mu}_{z t}+\widehat{\bar{w}}_{t}+\hat{R}_{t}^{f}+\hat{H}_{t}-\hat{k}_{t}
$$

The loglinearized law of motion for capital is given by

$$
\widehat{\bar{k}}_{t+1}=(1-\delta) \frac{1}{\mu_{z}} \widehat{\bar{k}}_{t}-(1-\delta) \frac{1}{\mu_{z}} \hat{\mu}_{z t}+\left[1-(1-\delta) \frac{1}{\mu_{z}}\right] \hat{\Upsilon}_{t}+\left[1-(1-\delta) \frac{1}{\mu_{z}}\right] \widehat{\tilde{\imath}}_{t}
$$

The output gap satisfies,

$$
\hat{y}_{t}=\lambda_{d} \hat{\epsilon}_{t}+\lambda_{d} \alpha \hat{k}_{t}-\lambda_{d} \alpha \hat{\mu}_{z t}+\lambda_{d}(1-\alpha) \hat{H}_{t}
$$

where $\lambda_{d}$ is the steady-state markup.

By combining the first-order conditions for the holdings of domestic and foreign bonds, we obtain the modified uncovered interest parity (UIP) condition,

$$
\left(1-\tilde{\phi}_{s}\right) \mathrm{E}_{t} \Delta \hat{S}_{t+1}-\tilde{\phi}_{s} \Delta \hat{S}_{t}-\left(\hat{R}_{t}-\hat{R}_{t}^{*}\right)-\tilde{\phi}_{a} \hat{a}_{t}+\widehat{\tilde{\phi}}_{t}=0
$$

The real exchange rate, $\tilde{x}_{t}$, satisfies

$$
\widehat{\tilde{x}}_{t} \equiv \hat{S}_{t}+\hat{P}_{t}^{*}-\hat{P}_{t}^{c} \equiv \widehat{\tilde{x}}_{t-1}+\hat{\pi}_{t}^{*}-\hat{\pi}_{t}^{c}
$$

The loglinearized version of the first-order conditions for money balances $m_{t+1}$ and cash holdings $q_{t}$ are, respectively,

$$
\begin{gathered}
-\mu \hat{\psi}_{z t}+\mu \hat{\psi}_{z, t+1 \mid t}-\mu \hat{\mu}_{z, t+1 \mid t}+\left(\mu-\beta \tau^{k}\right) \hat{R}_{t}-\mu \hat{\pi}_{t+1 \mid t}^{d}+\frac{\tau^{k}}{1-\tau^{k}}(\beta-\mu) \hat{\tau}_{t+1 \mid t}^{k}=0, \\
\hat{q}_{t}=\frac{1}{\sigma_{q}}\left[\hat{\zeta}_{t}^{q}+\frac{\tau^{k}}{1-\tau^{k}} \hat{\tau}_{t}^{k}-\hat{\psi}_{z t}-\frac{R}{R-1} \hat{R}_{t-1}\right]
\end{gathered}
$$

where $\mu$ is steady-state money growth and $\hat{\zeta}_{t}^{q}$ is a cash preference shock, to be specified below. 
The following aggregate resource constraint must hold in equilibrium

$$
\begin{gathered}
\left(1-\omega_{c}\right)\left(\gamma^{c d}\right)^{\eta_{c}} \frac{c}{y}\left(\hat{c}_{t}+\eta_{c} \hat{\gamma}_{t}^{c d}\right)+\left(1-\omega_{i}\right)\left(\gamma^{i d}\right)^{\eta_{i}} \frac{\tilde{\imath}}{y}\left(\hat{\tilde{\imath}}_{t}+\eta_{i} \hat{\gamma}_{t}^{i d}\right)+\frac{g}{y} \hat{g}_{t}+\frac{y^{*}}{y}\left(\hat{y}_{t}^{*}-\eta_{f} \hat{\gamma}_{t}^{x *}+\widehat{\widetilde{z}}_{t}^{*}\right) \\
=\lambda_{d}\left[\hat{\varepsilon}_{t}+\alpha\left(\hat{k}_{t}-\hat{\mu}_{z t}\right)+(1-\alpha) \hat{H}_{t}\right]-\left(1-\tau^{k}\right) r^{k} \frac{\bar{k}}{y} \frac{1}{\mu_{z}}\left(\hat{k}_{t}-\hat{\bar{k}}_{t}\right) ;
\end{gathered}
$$

where $\eta_{c}, \eta_{i}$, and $\eta_{f}$ are elasticities of substitution between domestic and imported consumer goods, domestic and imported investment goods, and domestic and foreign goods (in foreign consumption), respectively; $c, \tilde{\imath}, y, y^{*}, g$, and $\bar{k}$ are steady-state levels of consumption, investment, domestic output, foreign output, government expenditure, and the capital stock, respectively (when scaled with $z_{t}$, the technology level); $\hat{g}_{t}$ is government expenditure, and

$$
\hat{\gamma}_{t}^{i d} \equiv \hat{P}_{t}^{i}-\hat{P}_{t}^{d} \equiv \hat{\gamma}_{t-1}^{i d}+\hat{\pi}_{t}^{i}-\hat{\pi}_{t}^{d}
$$

is the relative price between investment and domestically produced goods.

We also need to relate money growth $\mu_{t}$ to real balances (where real balances $\bar{m}_{t+1} \equiv\left(M_{t+1} / P_{t}^{d}\right) / z_{t}$ are scaled by the technology shock $z_{t}$ and $M_{t+1}$ denote nominal balances) and domestic inflation,

$$
\mu_{t} \equiv \frac{M_{t+1}}{M_{t}} \equiv \frac{\bar{m}_{t+1} z_{t} P_{t}^{d}}{\bar{m}_{t} z_{t-1} P_{t-1}^{d}} \equiv \frac{\bar{m}_{t+1} \mu_{z t} \pi_{t}^{d}}{\bar{m}_{t}}
$$

Loglinearizing, we have

$$
\widehat{\bar{m}}_{t+1}=\widehat{\bar{m}}_{t}-\hat{\mu}_{z t}+\hat{\mu}_{t}-\hat{\pi}_{t}^{d}
$$

To clear the loan market, the demand for liquidity from the firms (which are financing their wage bills) must equal the supplied deposits of the households plus the monetary injection by the central bank:

$$
\nu \bar{w} H\left(\hat{\nu}_{t}+\widehat{\bar{w}}_{t}+\hat{H}_{t}\right)=\frac{\mu \bar{m}}{\pi^{d} \mu_{z}}\left(\hat{\mu}_{t}+\widehat{\bar{m}}_{t}-\hat{\pi}_{t}^{d}-\hat{\mu}_{z t}\right)-q \hat{q}_{t},
$$

where $\bar{w}, \bar{m}$ and $q$ are steady-state levels of real wages, real balances, and cash holdings (when scaled by $\left.z_{t}\right), H$ is the steady-state level of hours worked, and $\pi^{d}$ is the steady-state inflation of domestic goods.

The evolution of net foreign assets at the aggregate level satisfies

$$
\begin{aligned}
\hat{a}_{t}= & -y^{*} \widehat{\mathrm{mc}}_{t}^{x}-\eta_{f} y_{t}^{*} \hat{\gamma}_{t}^{x *}+y^{*} \hat{y}_{t}^{*}+y^{*} \widehat{\widetilde{z}}_{t}^{*}+\left(c^{m}+\tilde{\imath}^{m}\right) \hat{\gamma}_{t}^{f} \\
& -c^{m}\left[-\eta_{c}\left(1-\omega_{c}\right)\left(\gamma^{c d}\right)^{-\left(1-\eta_{c}\right)} \hat{\gamma}_{t}^{\mathrm{mc} d}+\hat{c}_{t}\right] \\
& -\tilde{\imath}^{m}\left[-\eta_{i}\left(1-\omega_{i}\right)\left(\gamma^{i d}\right)^{-\left(1-\eta_{i}\right)} \hat{\gamma}_{t}^{\mathrm{mid}}+\widehat{\tilde{\imath}}_{t}\right]+\frac{R}{\pi \mu_{z}} \hat{a}_{t-1} ;
\end{aligned}
$$


where $c^{m}$ and $i^{m}$ are steady-state levels of consumption and investment of imported goods (when scaled by $z_{t}$ ), $R$ is the steady-state nominal interest-rate level, and $\widehat{\widetilde{z}}_{t}^{*}$ is a stationary shock that measures the degree of asymmetry in the technological level between the domestic economy and the foreign economy.

The exogenous shocks of the model are AR(1) given by the representation

$$
\hat{\varsigma}_{t}=\rho_{\varsigma} \hat{\varsigma}_{t-1}+\varepsilon_{\varsigma t}
$$

where $\varepsilon_{\varsigma t}$ is i.i.d. and $N\left(0, \sigma_{\varsigma}^{2}\right)$, for $\varsigma_{t} \in\left\{\mu_{z t}, \varepsilon_{t}, \lambda_{t}^{j}, \zeta_{t}^{c}, \zeta_{t}^{h}, \zeta^{q}, \Upsilon_{t}, \tilde{\phi}_{t}, \bar{\pi}_{t}^{c}, \tilde{z}_{t}^{*}\right\}$ and $j \in\{d, \mathrm{mc}, \mathrm{mi}, x\}$. Furthermore, as discussed in ALLV [3], for estimation purposes it is convenient to rescale the markup shock $\hat{\lambda}_{t}^{j} j=\{d, \mathrm{mc}, \mathrm{mi}, x\}$ in the Phillips curves so as to include the coefficient $\frac{\left(1-\xi_{j}\right)\left(1-\beta \xi_{j}\right)}{\xi_{j}\left(1+\kappa_{j} \beta\right)}$ in the markup shock. Then the new coefficient on them in the Phillips curve is unity. Similarly, we rescale the investment specific technology shock $\hat{\Upsilon}_{t}$, the labor supply shock $\zeta_{t}^{h}$, and the consumption preference shock $\zeta_{t}^{c}$, so that these shocks enter in an additive fashion as well. ${ }^{25}$

The fiscal policy variables are assumed to be exogenously given by an identified VAR model with two lags and an uninformative prior. Let $\tau_{t} \equiv\left(\hat{\tau}_{t}^{k}, \hat{\tau}_{t}^{y}, \hat{\tau}_{t}^{c}, \hat{\tau}_{t}^{w}, \hat{g}_{t}\right)^{\prime}$, where $\hat{g}_{t}$ denotes HP-detrended government expenditures. The fiscal policy $\operatorname{VAR}(2)$-model is given by

$$
\Theta_{0} \tau_{t}=\Theta_{1} \tau_{t-1}+\Theta_{2} \tau_{t-2}+S_{\tau} \varepsilon_{\tau t}
$$

where $\varepsilon_{\tau t} \sim N\left(0, I_{\tau}\right) S_{\tau}$ is a diagonal matrix with the standard deviations, and $\Theta_{0}^{-1} S_{\tau} \varepsilon_{\tau t} \sim$ $N\left(0, \Sigma_{\tau}\right)$.

The foreign economy is exogenously given by an identified VAR model with four lags using an uninformative prior,

$$
\Phi_{0} X_{t}^{*}=\Phi_{1} X_{t-1}^{*}+\Phi_{2} X_{t-2}^{*}+\Phi_{3} X_{t-3}^{*}+\Phi_{4} X_{t-4}^{*}+S_{x^{*}} \varepsilon_{x^{*} t},
$$

where $X_{t}^{*} \equiv\left(\pi_{t}^{*}, \hat{y}_{t}^{*}, R_{t}^{*}\right)^{\prime}$, where $\pi_{t}^{*}$ and $R_{t}^{*}$ are quarterly foreign inflation and interest rates, and $\hat{y}_{t}^{*}$ is foreign output; $\varepsilon_{x^{*} t} \sim N\left(0, I_{x^{*}}\right) ; S_{X^{*}}$ is a diagonal matrix with the standard deviations; and $\Phi_{0}^{-1} S_{x^{*}} \varepsilon_{x^{*} t} \sim N\left(0, \Sigma_{x^{*}}\right){ }^{26}$ When estimating the VAR, we assume and do not reject that $\Phi_{0}$ in

\footnotetext{
25 Although this is not of any major importance for the baseline estimation of the model in ALLV [3], it is important when carrying out the sensitivity analysis there because the effective prior standard deviation of the shocks changes with the value of the nominal and real friction parameters. Smets and Wouters [27] adopt the same strategy. Therefore, to obtain the size of the four truly fundamental markup shocks, the estimated standard deviations reported in table 3.1 should be divided by their respective scaling parameter (for instance, $\frac{\left(1-\xi_{d}\right)\left(1-\beta \xi_{d}\right)}{\xi_{d}\left(1+\kappa_{d} \beta\right)}$ in the case of the domestic markup shock).

${ }^{26}$ The reason why we include foreign output HP-detrended and not in growth rates in the VAR is that the foreign output gap enters the log-linearized model (for instance, in the aggregate resource constraint). This also enables identification of the asymmetric technology shock.
} 
(A.12) has the following structure

$$
\Phi_{0} \equiv\left[\begin{array}{ccc}
1 & 0 & 0 \\
0 & 1 & 0 \\
-\gamma_{\pi 0}^{*} & -\gamma_{y 0}^{*} & 1
\end{array}\right]
$$

The model can then be written on the form (2.21), where the specification of the predetermined variables $X_{t}$, the forward-looking variables $x_{t}$, the policy instrument $i_{t}$, and the shock vector $\varepsilon_{t}$ can be found in the technical appendix [1].

\section{B. Optimal projections in some detail}

\section{B.1. Information and data}

First we clarify the information assumptions underlying the conditional expectation $\mathrm{E}_{t}$ used in the loss function (2.18). Let $\mathrm{E}_{t}[\cdot] \equiv \mathrm{E}\left[\cdot \mid \mathcal{I}_{t}\right]$ where $\mathcal{I}_{t}$ denotes the information set in period $t$. In the standard and simple case when all variables are observed, we can specify

$$
\mathcal{I}_{t} \equiv\left\{\varepsilon_{t}, X_{t}, i_{t} ; \varepsilon_{t-1}, X_{t-1}, x_{t-1}, i_{t-1} ; \varepsilon_{t-2}, X_{t-2}, x_{t-2}, i_{t-1} ; \ldots\right\}
$$

This can be interpreted as information in the beginning of period $t$. We can understand this as the agents of the model (the central bank, the private sector, the fiscal authority, and the rest of the world) entering the beginning of period $t$ with the knowledge of past realizations of shocks, variables, and instruments, $C \varepsilon_{t-1}, X_{t-1}, x_{t-1}, i_{t-1}, C \varepsilon_{t-2}, X_{t-2}, x_{t-2}, i_{t-2}, \ldots{ }^{27}$ Then, at the beginning of period $t$, the shock $\varepsilon_{t}$ is realized and observed, and $X_{t}$ is determined by $(2.22)$ and observed. We also assume that the agents know the model, including the matrices $A, B, C$, $D, H$, and $W$ and the scalar $\delta$, so either $C \varepsilon_{t}$ or $X_{t}$ is sufficient for inferring the other from (2.22), given that previous realizations are known. Then the central bank determines, announces, and implements its instrument setting, $i_{t}$, which is hence observed by the other agents. After this, the expectations $x_{t+1 \mid t}$ are formed, and $x_{t}$ is determined by (2.24). ${ }^{28}$ In equilibrium, both $i_{t}$ and $x_{t}$ will be a function of $X_{t}$ and previous realizations of $X_{t}$, consistent with this specification of the information set.

However, Ramses makes more elaborate and realistic information assumptions as shown in section 5.1. The variables $X_{t}$ and $x_{t}$ include (serially correlated) shocks and some other unobservable variables for which no data exists. Furthermore, the elements of $X_{t}, x_{t}$, and $i_{t}$ are in many cases quarterly averages, which have not been realized until the end of quarter $t$.

${ }^{27}$ Only the linear combination $C \varepsilon_{t}$ of the shocks $\varepsilon_{t}$ matters, not the individal shocks $\varepsilon_{t}$.

28 More precisely, the expectations $x_{t+1 \mid t}$ and $x_{t}$ are simultaneously determined. 


\section{B.2. Solving for the optimal projection}

As shown in Svensson [30], the $\left(n_{X}+n_{x}+n_{i}\right)$ first-order conditions for minimizing (2.18) under commitment subject to $(2.21)$ can be written

$$
\bar{A}^{\prime}\left[\begin{array}{c}
\xi_{t+1 \mid t} \\
\Xi_{t}
\end{array}\right]=\bar{W}\left[\begin{array}{c}
X_{t} \\
x_{t} \\
i_{t}
\end{array}\right]+\frac{1}{\delta} \bar{H}^{\prime}\left[\begin{array}{c}
\xi_{t} \\
\Xi_{t-1}
\end{array}\right]
$$

where the elements of the $n_{X}$-vector $\xi_{t+1}$ are the Lagrange multipliers for the upper block of (2.21) (the dating of $\xi_{t+1}$ emphasizes that this is a restriction that applies in period $t+1$ ), the elements of the $n_{x}$-vector $\Xi_{t}$ are the Lagrange multipliers for the lower block of (2.21) (the dating of $\Xi_{t}$ emphasizes that this is restriction that applies in period $t$ ), and the matrices $\bar{A}, \bar{W}$, and $\bar{H}$ are defined by

$$
\bar{A} \equiv[A B], \quad \bar{W} \equiv D^{\prime} W D, \quad \bar{H} \equiv\left[\begin{array}{ccc}
I & 0 & 0 \\
0 & H & 0
\end{array}\right]
$$

The first-order conditions can be combined with the $n_{X}+n_{x}$ model equations (2.21) to get a system of $2\left(n_{X}+n_{x}\right)+n_{i}$ difference equations for $t \geq 0$,

$$
\left[\begin{array}{cc}
\bar{H} & 0 \\
0 & \bar{A}^{\prime}
\end{array}\right]\left[\begin{array}{c}
X_{t+1} \\
x_{t+1 \mid t} \\
i_{t+1 \mid t} \\
\hline \xi_{t+1 \mid t} \\
\Xi_{t}
\end{array}\right]=\left[\begin{array}{cc}
\bar{A} & 0 \\
\bar{W} & \frac{1}{\delta} \bar{H}^{\prime}
\end{array}\right]\left[\begin{array}{c}
X_{t} \\
x_{t} \\
i_{t} \\
\hline \xi_{t} \\
\Xi_{t-1}
\end{array}\right]+\left[\begin{array}{c}
C \\
0 \\
\hline 0 \\
0
\end{array}\right] \varepsilon_{t+1}
$$

Here, $X_{t}$ and $\Xi_{t-1}$ are predetermined variables $\left(n_{X}+n_{x}\right.$ in total $)$, and $x_{t}, i_{t}$, and $\xi_{t}$ are nonpredetermined variables $\left(n_{x}+n_{i}+n_{X}\right.$ in total). This system can be rewritten as

$$
\left[\begin{array}{c}
\tilde{H}_{11} y_{1, t+1}+\tilde{H}_{12} y_{2, t+1 \mid t} \\
\tilde{H}_{21} y_{1, t+1 \mid t}+\tilde{H}_{22} y_{2, t+1 \mid t}
\end{array}\right]=\left[\begin{array}{cc}
\tilde{A}_{11} & \tilde{A}_{12} \\
\tilde{A}_{21} & \tilde{A}_{22}
\end{array}\right]\left[\begin{array}{c}
y_{1 t} \\
y_{2 t}
\end{array}\right]+\left[\begin{array}{c}
\tilde{C} \\
0
\end{array}\right] \varepsilon_{t+1},
$$

where $y_{1 t} \equiv\left(X_{t}^{\prime}, \Xi_{t-1}^{\prime}\right)^{\prime} \equiv \tilde{X}_{t}^{\prime}$ is the vector of predetermined variables and $y_{2 t} \equiv\left(x_{t}^{\prime}, i_{t}^{\prime}, \xi_{t}^{\prime}\right)^{\prime} \equiv\left(\tilde{x}_{t}^{\prime}, \xi_{t}^{\prime}\right)^{\prime}$ is the vector of non-predetermined variables. The matrices are defined as

$$
\begin{gathered}
\tilde{H}_{11} \equiv\left[\begin{array}{cc}
I & 0 \\
0 & A_{22}^{\prime}
\end{array}\right], \tilde{H}_{12} \equiv\left[\begin{array}{ccc}
0 & 0 & 0 \\
0 & 0 & A_{12}^{\prime}
\end{array}\right], \quad \tilde{H}_{21} \equiv\left[\begin{array}{cc}
0 & 0 \\
0 & A_{21}^{\prime} \\
0 & B_{2}^{\prime}
\end{array}\right], \quad \tilde{H}_{22} \equiv\left[\begin{array}{ccc}
H & 0 & 0 \\
0 & 0 & A_{11}^{\prime} \\
0 & 0 & B_{1}^{\prime}
\end{array}\right], \\
\tilde{A}_{11} \equiv\left[\begin{array}{cc}
A_{11} & 0 \\
\bar{W}_{x X} & \frac{1}{\delta} H^{\prime}
\end{array}\right], \quad \tilde{A}_{12} \equiv\left[\begin{array}{ccc}
A_{12} & B_{1} & 0 \\
\bar{W}_{x x} & \bar{W}_{x i} & 0
\end{array}\right], \tilde{A}_{21} \equiv\left[\begin{array}{cc}
A_{21} & 0 \\
\bar{W}_{X X} & 0 \\
\bar{W}_{i X} & 0
\end{array}\right], \\
\tilde{A}_{22} \equiv\left[\begin{array}{ccc}
A_{22} & B_{2} & 0 \\
\bar{W}_{X x} & \bar{W}_{X i} & \frac{1}{\delta} I \\
\bar{W}_{i x} & \bar{W}_{i i} & 0
\end{array}\right], \tilde{C} \equiv\left[\begin{array}{c}
C \\
0
\end{array}\right] .
\end{gathered}
$$


The solution to (B.4) can be written

$$
\begin{aligned}
y_{2 t} & \equiv\left[\begin{array}{c}
\tilde{x}_{t} \\
\xi_{t}
\end{array}\right]=F_{2} y_{1 t} \equiv\left[\begin{array}{c}
F \\
F_{\xi}
\end{array}\right] \tilde{X}_{t}, \\
y_{1, t+1} & \equiv \tilde{X}_{t+1}=M y_{1 t}+\tilde{H}_{11}^{-1} \tilde{C} \varepsilon_{t+1} \equiv M \tilde{X}_{t}+\tilde{H}_{11}^{-1} \tilde{C} \varepsilon_{t+1}
\end{aligned}
$$

for $t \geq 0$, where $y_{10} \equiv \tilde{X}_{0} \equiv\left(X_{0}^{\prime}, \Xi_{-1}^{\prime}\right)^{\prime}$ is given. We note that our assumption that $A_{22}$ is nonsingular implies that $\tilde{H}_{11}$ is nonsingular.

\section{B.3. Determination of the initial Lagrange multipliers}

As discussed in Svensson [29, Appendix A], ${ }^{29}$ the value of the initial Lagrange multiplier, $\Xi_{t-1, t}$, is zero, if there is commitment from scratch in period $t$, that is, if any previous commitment is disregarded. This reflects a time-consistency problem when there is reoptimization and recommitment in later periods, as is inherently the case in practical monetary policy. Instead, we assume that the optimization is under commitment in a timeless perspective. Then the commitment is considered having occurred some time in the past, and the initial value of the Lagrange multiplier satisfies

$$
\Xi_{t-1, t}=\Xi_{t-1, t-1}
$$

where $\Xi_{t-1, t-1}$ denotes the Lagrange multiplier of the lower block of (5.2) for the determination of $x_{t-1, t-1}$ in the decision problem in period $t-1$. The dependence of the optimal policy projection in period $t$ on this Lagrange multiplier from the decision problem in the previous period makes the optimal policy projection depend on previous projections and illustrates the history dependence of optimal policy under commitment in a forward-looking model shown in Backus and Driffill [9] and Currie and Levine [13] and especially examined and emphasized in Woodford [39].

We now discuss how to compute the initial Lagrange multiplier, $\Xi_{t-1, t}$ when no explicit optimization was done in previous periods. In doing so, we assume that past policy has been optimal. ${ }^{30}$

Note that (5.8) and (B.5) imply that, in real time, the Lagrange multiplier $\Xi_{t}$ satisfies

$$
\Xi_{t, t}=M_{\Xi X} X_{t \mid t}+M_{\Xi \Xi} \Xi_{t-1, t-1}=\sum_{\tau=0}^{T}\left(M_{\Xi \Xi}\right)^{\tau} M_{\Xi X} X_{t-\tau \mid t-\tau},
$$

if the commitment occurred from scratch in period $t-T$, so $\Xi_{t-T-1, t-T}=0$. Here $M$ is partitioned conformably with $X_{t}$ and $\Xi_{t-1}$ so

$$
M \equiv\left[\begin{array}{cc}
M_{X X} & M_{X \Xi} \\
M_{\Xi X} & M_{\Xi \Xi}
\end{array}\right]
$$

\footnotetext{
29 The appendix is availabale at www.larseosvensson.net.

${ }^{30}$ In the working paper version of the paper, we also consider another method which assumes that past policy has been systematic but not necessarily optimal. This method seems less restrictive but is not used in this paper.
} 
Recall that that $M$ will depend on the weight matrix $W$ in the period loss function and hence vary with the assumed or estimated loss function.

Given this, one possible initial value for $\Xi_{t-1, t}=\Xi_{t-1, t-1}$ is

$$
\Xi_{t-1, t-1}=\sum_{\tau=0}^{T}\left(M_{\Xi \Xi}\right)^{\tau} M_{\Xi X} X_{t-1-\tau \mid t-1-\tau} .
$$

This treats estimated realized $X_{t-\tau}(\tau=0,1, \ldots, T)$ as resulting from optimal policy under commitment. The lag $T$ may be chosen such that $\left(M_{\Xi \Xi}\right)^{T} M_{\Xi X}$ is sufficiently small.

\section{B.4. Projections with an arbitrary instrument rule}

With a constant (that is, time-invariant) arbitrary instrument rule, the instrument rate satisfies

$$
i_{t}=\left[\begin{array}{ll}
f_{X} & f_{x}
\end{array}\right]\left[\begin{array}{c}
X_{t} \\
x_{t}
\end{array}\right]
$$

for $\tau \geq 0$, where the $n_{i} \times\left(n_{X}+n_{x}\right)$ matrix $\left[\begin{array}{ll}f_{X} & f_{x}\end{array}\right]$ is a given (linear) instrument rule and partitioned conformably with $X_{t}$ and $x_{t} \cdot{ }^{31}$ If $f_{x} \equiv 0$, the instrument rule is an explicit instrument rule; if $f_{x} \neq 0$, the instrument rule is an implicit instrument rule. In the latter case, the instrument rule is actually an equilibrium condition, in the sense that in a real-time analogue the instrument rate in period $t$ and the forward-looking variables in period $t$ would be simultaneously determined.

An arbitrary more general (linear) policy rule $(G, f)$ can be written as

$$
G_{x} x_{t+1 \mid t}+G_{i} i_{t+1 \mid t}=f_{X} X_{t}+f_{x} x_{t}+f_{i} i_{t}
$$

where the $n_{i} \times\left(n_{x}+n_{i}\right)$ matrix $G \equiv\left[\begin{array}{ll}G_{x} & G_{i}\end{array}\right]$ is partitioned conformably with $x_{t}$ and $i_{t}$ and the $n_{i} \times\left(n_{X}+n_{x}+n_{i}\right)$ matrix $f \equiv\left[\begin{array}{lll}f_{X} & f_{x} & f_{i}\end{array}\right]$ is partitioned conformably with $X_{t}, x_{t}$, and $i_{t}$. This general policy rules includes explicit, implicit, and forecast-based instrument rules (in the latter the instrument rate depends on expectations of future forward-looking variables, $\left.x_{t+1 \mid t}\right)$ as well as targeting rules (conditions on current or expected future target variables). When this general policy rule is an instrument rule, we require the $n_{x} \times n_{i}$ matrix $f_{i}$ to be nonsingular, so (B.9) determines $i_{t}$ for given $X_{t}, x_{t}, x_{t+1 \mid t}$, and $i_{t+1 \mid t}$.

The general policy rule can be added to the model equations (2.21) to form the new system to be solved. With the notation $\tilde{x}_{t} \equiv\left(x_{t}^{\prime}, i_{t}^{\prime}\right)^{\prime}$, the new system can be written

$$
\left[\begin{array}{c}
X_{t+1} \\
\tilde{H} \tilde{x}_{t+1 \mid t}
\end{array}\right]=\tilde{A}\left[\begin{array}{c}
X_{t} \\
\tilde{x}_{t}
\end{array}\right]+\left[\begin{array}{c}
C \\
0_{\left(n_{x}+n_{i}\right) \times n_{\varepsilon}}
\end{array}\right] \varepsilon_{t+1},
$$

\footnotetext{
${ }^{31}$ For projections with arbitrary time-varying policy rules, see Laséen, and Svensson [18].
} 


$$
Y_{t}=D\left[\begin{array}{c}
X_{t} \\
\tilde{x}_{t}
\end{array}\right], \quad Z_{t}=\bar{D}\left[\begin{array}{c}
X_{t} \\
\tilde{x}_{t}
\end{array}\right]
$$

where

$$
\tilde{H} \equiv\left[\begin{array}{cc}
H & 0 \\
G_{x} & G_{i}
\end{array}\right], \quad \tilde{A} \equiv\left[\begin{array}{ccc}
A_{11} & A_{12} & B_{1} \\
A_{21} & A_{22} & B_{2} \\
f_{X} & f_{x} & f_{i}
\end{array}\right]
$$

where $\tilde{H}$ is partitioned conformably with $x_{t}$ and $i_{t}$ and $\tilde{A}$ is partitioned conformably with $X_{t}, x_{t}$, and $i_{t}$. The corresponding projection model can then be written

$$
\begin{gathered}
{\left[\begin{array}{c}
X_{t+\tau+1, t} \\
\tilde{H} \tilde{x}_{t+\tau+1, t}
\end{array}\right]=\tilde{A}\left[\begin{array}{c}
X_{t+\tau, t} \\
\tilde{x}_{t+\tau, t}
\end{array}\right],} \\
Y_{t+\tau, t}=D\left[\begin{array}{c}
X_{t+\tau, t} \\
\tilde{x}_{t+\tau, t}
\end{array}\right], \quad Z_{t+\tau, t}=\bar{D}\left[\begin{array}{c}
X_{t+\tau, t} \\
\tilde{x}_{t+\tau, t}
\end{array}\right]
\end{gathered}
$$

for $\tau \geq 0$, where $X_{t, t}=X_{t \mid t}$.

Then, (under the usual assumption that the policy rule gives rise to the standard saddlepoint property for the system's eigenvalues) there exist matrices $M$ and $F$ such that the resulting equilibrium projection satisfies

$$
\begin{gathered}
X_{t+\tau+1, t}=M X_{t+\tau, t} \\
\tilde{x}_{t+\tau, t} \equiv\left[\begin{array}{c}
x_{t+\tau, t} \\
i_{t+\tau, t}
\end{array}\right]=F X_{t+\tau, t} \equiv\left[\begin{array}{c}
F_{x} \\
F_{i}
\end{array}\right] X_{t+\tau, t}
\end{gathered}
$$

for $\tau \geq 0$, where the matrices $M$ and $F$ depend on $\tilde{A}$ and $\tilde{H}$, and thereby on $A, B, H, G$, and $f .{ }^{32}$

\section{Flexprice equilibrium and alternative concepts of potential output}

Under the assumption of flexible prices and wages and an additional equation that determines nominal variables (inflation, the price level, the exchange rate, or some other nominal variable), the flexprice model can be written

$$
\left[\begin{array}{c}
X_{t+1} \\
H^{f} x_{t+1 \mid t}
\end{array}\right]=A^{f}\left[\begin{array}{c}
X_{t} \\
x_{t} \\
i_{t}
\end{array}\right]+\left[\begin{array}{c}
C \\
0_{n_{x} \times n_{\varepsilon}} \\
0_{n_{i} \times n_{\varepsilon}}
\end{array}\right] \varepsilon_{t+1},
$$

\footnotetext{
${ }^{32}$ Equivalently, the resulting equilibrium projection satisfy

$$
\left[\begin{array}{c}
\check{X}_{t+\tau+1, t} \\
\check{x}_{t+\tau+1, t} \\
\check{i}_{t+\tau+1, t}
\end{array}\right]=\bar{B}\left[\begin{array}{c}
\check{X}_{t+\tau, t} \\
\check{x}_{t+\tau, t} \\
\check{i}_{t+\tau, t}
\end{array}\right]
$$

for $\tau \geq 0$, where

$$
\begin{aligned}
\check{X}_{t, t} & =X_{t \mid t} \\
{\left[\begin{array}{c}
\check{x}_{t, t} \\
\check{i}_{t, t}
\end{array}\right] } & =\left[\begin{array}{c}
\bar{B}_{x} \\
\bar{B}_{i}
\end{array}\right]\left[\begin{array}{c}
\check{X}_{t-1, t-1} \\
\check{x}_{t-1, t-1} \\
\check{i}_{t-1, t-1}
\end{array}\right]+\left[\begin{array}{c}
\Phi_{x X} \\
\Phi_{i X}
\end{array}\right]\left(X_{t \mid t}-\check{X}_{t, t-1}\right)
\end{aligned}
$$
}


with the same variables $X_{t}, x_{t}$, and $i_{t}$ and the same i.i.d. shocks $\varepsilon_{t}$ as in the sticky-price model but with the new $\left(n_{x}+n_{i}\right) \times n_{x}$ matrix $H^{f}$ and $\left(n_{X}+n_{x}+n_{i}\right) \times\left(n_{X}+n_{x}+n_{i}\right)$ matrix $A^{f}$. There are hence $n_{i}$ extra equations added to the lower block of the equations (the block of equations determining the forward-looking variables), as many equations as the number of policy instruments. The discussion here is restricted to the case $n_{i}=1$ (as is Ramses), so only one equation needs to be added, such as

$$
\hat{\pi}_{t}^{\mathrm{cpi}}=0 \text { or } \hat{\pi}_{t}^{d}=0
$$

In the latter case,

$$
H^{f} \equiv\left[\begin{array}{c}
H \\
0_{1 \times n_{x}}
\end{array}\right], \quad A^{f} \equiv\left[\begin{array}{ccc}
A_{11} & A_{12} & B_{1} \\
A_{21} & A_{22} & B_{2} \\
0_{1 \times n_{X}} & e_{1} & 0
\end{array}\right],
$$

where $e_{1}$ here denotes a row $n_{x}$-vector with the first element equal to unity and the other elements equal to zero (reflecting that domestic inflation, $\hat{\pi}_{t}^{d}$, is the first forward-looking variable).

The matrix $A^{f}$ has been modified so there is no effect on the endogenous variables of the four time-varying markups $\hat{\lambda}_{j}, j \in\{d, \mathrm{mc}, \mathrm{mi}, x\}$, since these time-varying distortions would introduce undesirable variation in the difference between the (loglinearized) efficient and flexprice output. This is achieved by setting the corresponding elements in $A_{11}$ and $A_{21}$ equal to zero. With the same argument one may also want to eliminate the effect on the endogenous variables of timevarying tax rates.

Let $\tilde{x}_{t}^{f} \equiv\left(x_{t}^{f \prime}, i_{t}^{f \prime}\right)^{\prime}$ and $X_{t}^{f}$ denote the realizations of the nonpredetermined and predetermined variables, respectively, in a flexprice equilibrium for $t \geq t_{0}$, where $t_{0}$ is some period in the past with given predetermined variables $X_{t_{0}}$ from which we compute the flexprice equilibrium. The flexprice equilibrium is the solution to the system of difference equations (C.1) for $t \geq t_{0}$. It can be written

$$
\begin{aligned}
\tilde{x}_{t}^{f} & \equiv\left[\begin{array}{c}
x_{t}^{f} \\
i_{t}^{f}
\end{array}\right]=F^{f} X_{t}^{f} \equiv\left[\begin{array}{c}
F_{x}^{f} \\
F_{i}^{f}
\end{array}\right] X_{t}^{f}, \\
X_{t+1}^{f} & =M^{f} X_{t}^{f}+C^{f} \varepsilon_{t+1},
\end{aligned}
$$

for $t \geq t_{0}$, where $F^{f}$ and $M^{f}$ are matrices returned by the Klein [21] algorithm and $X_{t_{0}}^{f}=X_{t_{0}}$. In particular, one of the elements of $x_{t}^{f}$ (and $\tilde{x}_{t}^{f}$ ) is $\hat{y}_{t}^{f}$, output in the flexprice equilibrium. We can therefore write flexprice output in period $t \geq t_{0}$ as

$$
\hat{y}_{t}^{f}=F_{y}^{f} \cdot X_{t}^{f}
$$

where the row vector $F_{y}^{f}$. is the row of the matrix $F^{f}$ that corresponds to output. 


\section{C.1. Unconditional potential output}

Consider now a hypothetical flexprice equilibrium that has lasted forever, the unconditional flexprice equilibrium. The hypothetical realization of the predetermined variables in period $t$, denoted $X_{t ;-\infty}^{f}$, then satisfies

$$
X_{t ;-\infty}^{f}=M^{f} X_{t-1 ;-\infty}^{f}+C^{f} \varepsilon_{t}=\sum_{s=0}^{\infty}\left(M^{f}\right)^{s} C^{f} \varepsilon_{t-s},
$$

and hence depends on the realizations of the shocks $\varepsilon_{t}, \varepsilon_{t-1}, \ldots$ The corresponding flexprice output is

$$
\hat{y}_{t ;-\infty}^{f} \equiv F_{y}^{f} X_{t ;-\infty}^{f}=F_{y}^{f} \sum_{s=0}^{\infty}\left(M^{f}\right)^{s} C^{f} \varepsilon_{t-s} .
$$

We refer to this output level as unconditional potential output. It hence corresponds to the output level in a hypothetical economy that has always had flexible prices and wages but is subject to the same shocks as the actual economy. It hence has a different capital stock and different realizations of the endogenous both predetermined and nonpredetermined variables compared to the actual economy. It corresponds to the natural rate of output consistent with the definition of the natural rate of interest in Neiss and Nelson [22].

\section{C.2. Conditional potential output}

Consider also the hypothetical situation in which prices and wages in the actual economy unexpectedly become flexible in the current period $t$ and are then expected to remain flexible forever. The corresponding flexprice output in this economy is denoted $\hat{y}_{t ; t}^{f}$ and given by

$$
\hat{y}_{t ; t}^{f} \equiv F_{y}^{f} X_{t}
$$

We refer to this output level as conditional potential output (conditional on prices and wages becoming flexible in the same period and therefore conditional on the existing predetermined variables, including the capital stock). It corresponds to the definition of the natural rate of output presented in Woodford [39, section 5.3.4].

We then realize that we can define conditional-h potential output, where $h \in\{0,1, \ldots\}$ refers to prices and wages unexpectedly becoming flexible and expected to remain flexible forever in period

$t-h$, that is, $h$ periods before $t$. This concept of potential output is denoted $\hat{y}_{t ; t-h \mid t}^{f}$ and is given by

$$
\hat{y}_{t ; t-h}^{f} \equiv F_{y}^{f} \cdot X_{t ; t-h}^{f} \equiv F_{y}^{f} \cdot\left(M^{f} X_{t-1 ; t-h}^{f}+C^{f} \varepsilon_{t}\right) \equiv F_{y}^{f} \cdot\left[\left(M^{f}\right)^{h} X_{t-h}+\sum_{s=0}^{h-1}\left(M^{f}\right)^{s} C^{f} \varepsilon_{t-s}\right] .
$$


Conditional- $h$ potential output hence depends on the state of the economy (the predetermined variables) in period $t-h$ and the shocks from $t-h+1$ to $t$. Conditional-0 potential output is obviously the same as conditional potential output. Unconditional potential output is the limit of conditional- $h$ potential output when $h$ goes to infinity,

$$
\hat{y}_{t ;-\infty}^{f}=\lim _{h \rightarrow \infty} \hat{y}_{t ; t-h}^{f}
$$

\section{C.3. Projections of potential output}

Consider now projections in period $t$ of these alternative concepts of potential output. The projection in period $t$ of unconditional potential output, $\left\{\hat{y}_{t+\tau ;-\infty, t}^{f}\right\}_{\tau=0}^{\infty}$ (where the first subindex, $t+\tau$, refers to the future period for which potential output is projected; the second subindex, $-\infty$, indicates that unconditional potential output is considered; and the third subindex, $t$, refers to the period in which the projection is made and for which information is available), is related to the projection of the unconditional flexprice predetermined variables, $\left\{X_{t+\tau ;-\infty, t}^{f}\right\}_{\tau=0}^{\infty}$, and is given by

$$
\hat{y}_{t+\tau ;-\infty, t}^{f} \equiv F_{y \cdot}^{f} X_{t+\tau ;-\infty, t}^{f} \equiv F_{y \cdot}^{f}\left(M^{f}\right)^{\tau} X_{t ;-\infty \mid t}^{f}
$$

for $\tau \geq 0$, where $X_{t ;-\infty \mid t}^{f}$ denotes the estimated realization of the unconditional flexprice predetermined variables in period $t$ conditional on information available in period $t$.

Here, $X_{t ;-\infty \mid t}^{f}$ can be estimated from

$$
X_{t ;-\infty \mid t}^{f}=\left(M^{f}\right)^{t-t_{0}} X_{t_{0} \mid t}+\sum_{s=0}^{t-1-t_{0}}\left(M^{f}\right)^{s} C^{f} \varepsilon_{t-s \mid t},
$$

where the unconditional flexprice equilibrium is approximated by a flexprice equilibrium that starts in a particular period $t_{0}<t, X_{t_{0} \mid t}$ denotes the estimate conditional on information available in period $t$ of the predetermined variables in period $t_{0}$, and $\varepsilon_{t-s \mid t}$ denotes the estimate conditional in information available in period $t$ of the realization of the shock in period $t-s$.

The projection in period $t$ of conditional potential output (that is, conditional-0 potential output), $\left\{\hat{y}_{t+\tau ; t+\tau, t}^{f}\right\}_{\tau=0}^{\infty}$, is given by

$$
\hat{y}_{t+\tau ; t+\tau, t}^{f} \equiv F_{y}^{f} \cdot X_{t+\tau, t}
$$

for $\tau \geq 0$. Note that the projection of conditional potential output in period $t+\tau$ then refers to the flexprice output for a flexprice equilibrium that starts in the future period $t+\tau$, not in the current period period $t$. In the latter case, it would instead be the projection of conditional- $\tau$ potential output in period $t+\tau$. Therefore, the projection of the predetermined variables in period $t+\tau$ of 
the actual economy, $X_{t+\tau, t}$, enters in (C.8), not the projection of the predetermined variables in period $t+\tau$ of the flexprice equilibrium starting in period $t, X_{t+\tau ; t, t}^{f}$.

The projection in period $t$ of conditional-h potential output, $\left\{\hat{y}_{t+\tau ; t+\tau-h, t}^{f}\right\}_{\tau=0}^{\infty}$, is related to the projection of the conditional- $h$ flexprice predetermined variables, $\left\{X_{t+\tau ; t+\tau-h, t}^{f}\right\}_{\tau=0}^{\infty}$, and is given by

$$
\hat{y}_{t+\tau ; t+\tau-h, t}^{f} \equiv F_{y}^{f} X_{t+\tau ; t+\tau-h, t}^{f}
$$

for $\tau \geq 0$. That is, the projection of the conditional- $h$ predetermined variables in period $t+\tau$ enters in (C.9), the predetermined variables in the flexprice equilibrium that starts $h$ periods earlier, in period $t+\tau-h$. Furthermore, this projection is given by

$$
X_{t+\tau ; t+\tau-h, t}^{f} \equiv\left(M^{f}\right)^{h} X_{t+\tau-h, t}+\sum_{s=\tau}^{h-1}\left(M^{f}\right)^{s} C^{f} \varepsilon_{t+\tau-s \mid t},
$$

where the summation term is zero when $\tau \geq h$. Thus, the projection in period $t$ of the realization of conditional- $h$ potential output in period $t+\tau, \hat{y}_{t+\tau ; t+\tau-h, t}^{f}$, depends on the projection of the predetermined variables in period $t+\tau-h$ of the actual economy (with sticky prices and wages), $X_{t+\tau-h, t}$, and when $\tau<h$ also on the estimated shocks $\varepsilon_{t-s \mid t}$ for $s=0,1, \ldots, h-\tau-1$. (For $\tau>h$, $\left.\varepsilon_{t+\tau-h \mid t}=0\right)$.

\section{C.4. Output gaps}

We can then consider several concepts of output gaps: We have the trend output gap, the gap between actual output and trend output, $\hat{y}_{t}$ (recall that $\hat{y}_{t}$ is the deviation from trend). For each concept of potential output, we have a corresponding concept of output gap: The unconditional output gap,

$$
\hat{y}_{t}-y_{t ;-\infty}^{f} \equiv \hat{y}_{t}-F_{y}^{f} \cdot X_{t ;-\infty}^{f}
$$

the conditional output gap,

$$
\hat{y}_{t}-y_{t ; t}^{f} \equiv \hat{y}_{t}-F_{y}^{f} \cdot X_{t}
$$

and the conditional-h output gap,

$$
\hat{y}_{t}-y_{t ; t-h}^{f} \equiv \hat{y}_{t}-F_{y}^{f} X_{t ; t-h}^{f}
$$

The projections of the different output gaps are then defined in analogy with the projections of the different potential outputs. 


\section{References}

[1] Adolfson, Malin, Stefan Laséen, Jesper Lindé, and Lars E.O. Svensson (2008a), "Optimal Monetary Policy in an Operational Medium-Sized Model: Technical Appendix," working paper, www.larseosvensson.net.

[2] Adolfson, Malin, Stefan Laséen, Jesper Lindé, and Lars E.O. Svensson (2008b), "Monetary Policy Trade-Offs in an Open-Economy DSGE Model," Sveriges Riksbank Working Paper No. 232, www.riksbank.com.

[3] Adolfson, Malin, Stefan Laséen, Jesper Lindé, and Mattias Villani (2008), "Evaluating an Estimated New Keynesian Small Open Economy Model," Journal of Economic Dynamics and Control 32(8), 2690-2721.

[4] Adolfson, Malin, Stefan Laséen, Jesper Lindé, and Mattias Villani (2007a), "Bayesian Estimation of an Open Economy DSGE Model with Incomplete Pass-Through,", Journal of International Economics 72(2), 481-511.

[5] Adolfson, Malin, Stefan Laséen, Jesper Lindé, and Mattias Villani (2007b), "RAMSES - a New General Equilibrium Model for Monetary Policy Analysis," Sveriges Riksbank Economic Review 2/2007, 5-39, www.riksbank.com.

[6] Adolfson, Malin and Jesper Lindé (2009), "Parameter Identification in an Estimated New Keynesian Open Economy Model", mimeo, Sveriges Riksbank.

[7] Adolfson, Malin, Jesper Lindé and Mattias Villani (2007), "Forecasting Performance of an Open Economy DSGE Model", Econometric Reviews 26(2-4), 289-328.

[8] Altig, David, Lawrence Christiano, Martin Eichenbaum and Jesper Lindé (2003), "The Role of Monetary Policy in the Propagation of Technology Shocks," manuscript, Northwestern University.

[9] Backus, David, and John Driffill (1986), "The Consistency of Optimal Policy in Stochastic Rational Expectations Models," CEPR Discussion Paper No. 124.

[10] Calvo, Guillermo (1983), "Staggered Prices in a Utility Maximizing Framework," Journal of Monetary Economics 12, 383-398. 
[11] Christiano, Lawrence J., Martin Eichenbaum and Charles Evans (2005), "Nominal Rigidities and the Dynamic Effects of a Shock to Monetary Policy," Journal of Political Economy 113(1), $1-45$.

[12] Christiano, Lawrence J., Mathias Trabandt and Karl Walentin (2011) "Introducing Financial Frictions and Unemployment into a Small Open Economy Model.” Sveriges Riksbank Working Paper No. 214, www.riksbank.com.

[13] Currie, David, and Paul Levine (1993), Rules, Reputation and Macroeconomic Policy Coordination, Cambridge University Press.

[14] Del Negro, Marco, Frank Schorfheide, Frank Smets and Raf Wouters (2007), "On the Fit and Forecasting Performance of New Keynesian Models," Journal of Business and Economic Statistics 25(2), 123-143.

[15] Duarte, Margarida, and Alan Stockman (2005), "Rational speculation and exchange rates," Journal of Monetary Economics 52, 3-29.

[16] Erceg, Christopher, Dale Henderson and Andrew Levin, (2000) "Optimal Monetary Policy with Staggered Wage and Price Contracts," Journal of Monetary Economics 46(2), 281-31.

[17] Justiniano, Alejandro and Bruce Preston (2010), "Can Structural Small Open Economy Models Account for the Influence of Foreign Disturbances," Journal of International Economics 81(1), $61-74$.

[18] Laséen, Stefan, and Lars E.O. Svensson (2009), "Anticipated Instrument-Rate Paths in Policy Simulations," working paper, www.larseosvensson.net.

[19] Lindé, Jesper (2003), "Monetary Policy Shocks and Business Cycle Fluctuations in a Small Open Economy: Sweden 1986-2002", Sveriges Riksbank Working Paper No. 153, www.riksbank.com.

[20] Levin, Andrew T., Alexei Onatski, John C. Williams, Noah Williams (2005), "Monetary Policy Under Uncertainty in Micro-Founded Macroeconometric Models", in eds. Gertler, Mark and Kenneth Rogoff, NBER Macroeconomics Annual, 229-312.

[21] Klein, Paul (2000), "Using the Generalized Schur Form to Solve a Multivariate Linear Rational Expectations Model," Journal of Economic Dynamics and Control 24, 1405-1423. 
[22] Neiss, Katherine S., and Edward Nelson (2003), "The Real Interest Rate Gap as an Inflation Indicator," Macroeconomic Dynamics 7, 239-262.

[23] Onatski, Alexei, and Noah Williams (2003), "Modeling Model Uncertainty," Journal of the European Economic Association 1, 1087-1022.

[24] Schmitt-Grohé, Stephanie and Martín Uribe (2001), "Stabilization Policy and the Cost of Dollarization," Journal of Money, Credit, and Banking 33(2), 482-509

[25] Sims, Christopher A. (2000), "Solving Linear Rational Expectations Models," www.princeton.edu/ $\sim \operatorname{sims} /$.

[26] Smets, Frank and Raf Wouters (2003), "An Estimated Stochastic Dynamic General Equilibrium Model of the Euro Area," Journal of the European Economic Association 1(5), 1123-1175.

[27] Smets, F. and R. Wouters (2007), "Shocks and Frictions in US Business Cycles: A Bayesian DSGE Approach," American Economic Review 97(3), 586-606.

[28] Söderlind, Paul (1999), "Solution and Estimation of RE Macromodels with Optimal Policy," European Economic Review 43, 813-823. Related software available at home.tiscalinet.ch/paulsoderlind.

[29] Svensson, Lars E.O. (2005), "Monetary Policy with Judgment: Forecast Targeting," International Journal of Central Banking 1(1), 1-54, www.ijcb.org.

[30] Svensson, Lars E.O. (2007), "Optimization under Commitment and Discretion, the Recursive Saddlepoint Method, and Targeting Rules and Instrument Rules: Lecture Notes," www.larseosvensson.net.

[31] Svensson, Lars E.O. (2010), "Inflation Targeting," in Friedman, Benjamin M., and Michael Woodford, eds., Handbook of Monetary Economics, Volume $3 a$ and 3b, North-Holland, forthcoming.

[32] Svensson, Lars E.O. (2007), "Potential and Efficient Output," research notes.

[33] Svensson, Lars E.O., and Noah Williams (2007a), "Monetary Policy with Model Uncertainty: Distribution Forecast Targeting," working paper, www.larseosvensson.net. 
[34] Svensson, Lars E.O., and Noah Williams (2007b), "Bayesian and Adaptive Optimal Policy under Model Uncertainty," working paper, www.larseosvensson.net.

[35] Svensson, Lars E.O., and Robert J. Tetlow (2005), "Optimal Policy Projections," International Journal of Central Banking 1(3), 177-207, www.ijcb.org.

[36] Svensson, Lars E.O., and Michael Woodford (2004), "Indicator Variables for Optimal Policy under Asymmetric Information," Journal of Economic Dynamics and Control 28, 661-690.

[37] Sveriges Riksbank (2010), Monetary Policy in Sweden, www.riksbank.se.

[38] Wolden Bache, Ida, Leif Brubakk, and Junior Maih (2008), "Estimating a DSGE Model for Norway with Optimal Monetary Policy," working paper, Norges Bank.

[39] Woodford, Michael (2003), Interest Rates and Prices, Princeton University Press. 